\title{
Efficient Preparation of Nanoparticle-Reinforced Nickel-based Composite Coating with Highly Preferred (220) Orientation
}

Renjie Ji ${ }^{1} \mathbb{C}$, Hui Jin ${ }^{1}$, Yonghong Liu ${ }^{1} 2^{*}$, Tiancong Dong ${ }^{1}$, Fan Zhang ${ }^{1}$, Lilong Zhao ${ }^{1}$, Xinlei Wu ${ }^{1}$, Qiang Sun ${ }^{1}$, Peng Liu' ${ }^{1}$, Hang Dong ${ }^{1}$, Chi Ma', Dege Li ${ }^{1}$ and Baoping Cai ${ }^{1}$

\begin{abstract}
Nanoparticle-reinforced metal matrix composite coatings have significant potential in mechanical part surface strengthening owing their excellent mechanical properties. This paper reports a phenomenon in which the grain orientation gradually evolves to (220) as the deposition current density increases when preparing nanoparticlereinforced nickel-based composite coatings through jet electrodeposition (JED). During the preparation of the Ni-SiC composite coatings, the deposition current density increased from $180 \mathrm{~A} / \mathrm{dm}^{2}$ to $220 \mathrm{~A} / \mathrm{dm}^{2}$, and TC(220) gradually increase from $41.4 \%$ to $97.7 \%$. With an increase of TC(220), the self-corrosion potential increases from -0.575 to $-0.477 \mathrm{~V}$, the corrosion current density decreases from $9.52 \mu \mathrm{A} / \mathrm{cm}^{2}$ to $2.76 \mu \mathrm{A} / \mathrm{cm}^{2}$, the diameter of the corrosion pits that after 10 days of immersion in a $3.5 \mathrm{wt} \% \mathrm{NaCl}$ solution decreases from 278-944 nm to $153-260 \mathrm{~nm}$, and the adhesion of the coating increases from $24.9 \mathrm{~N}$ to $61.6 \mathrm{~N}$. Compared a conventional electrodeposition (CED), the Ni-SiC composite coating using JED has the advantages of a smooth surface morphology, high corrosion resistance, and strong adhesion, which are more obvious with an increase in TC(220).
\end{abstract}

Keywords: Jet electrodeposition, Composite coating, Preferred orientation, Adhesion force, Corrosion resistance

\section{Introduction}

With the continuous development of modern industry, the wear and corrosion resistances of an increasing number of key components of high-end equipment are required; thus, high-performance composite coatings usually need to be prepared on the key component surface. Nanoparticle-reinforced metal matrix composite coatings have significant potential application in surface strengthening of mechanical parts owing to their excellent hardness, abrasion resistance, corrosion resistance,

\footnotetext{
*Correspondence: liuyhupc@163.com

${ }^{\dagger}$ Renjie Ji and Hui Jin contributed equally to this work and should be considered as co-first authors

${ }^{1}$ College of Mechanical and Electronic Engineering, China University of Petroleum (East China), Qingdao 266580, China

Full list of author information is available at the end of the article
}

and high-temperature oxidation resistance. Researchers are widely concerned with this issue. $\mathrm{Li}$ et al. [1] produced a $\mathrm{Ni}-\mathrm{SiO}_{2}$ composite coating by electrodeposition and found that the addition of $\mathrm{SiO}_{2}$ nanoparticles improves the wear resistance of the coating. Li et al. [2] prepared a Ni-W/TiN coating by pulse electrodeposition and observed that the doped TiN nanoparticles promote nucleation and cause obvious changes in the microstructure, thus improving the hardness and corrosion resistance of the coating. Tao et al. [3] fabricated a $\mathrm{Ni}$-B-Sc coating using conventional electrodeposition and detected that the grain boundary and phase boundary area increased owing to the addition of $\mathrm{Ni}_{2} \mathrm{Sc}$ nanoparticles. However, nanoparticles usually exist in the form of agglomeration in the plating solution because of their high surface energy. It is difficult to break the 
agglomeration of nanoparticles by conventional electrodeposition, and thus the prepared composite coatings have defects, such as rough surfaces and poor adhesion $[4,5]$.

JED is a type of unconventional electrodeposition. The high-speed jet liquid improves the transmission speed of ions in the deposition process compared with CED. The ions are evenly distributed by high-speed flushing, which reduces the concentration polarization and improves the upper limit value of the current density during the electrodeposition process [6, 7]. Meanwhile, the agglomeration of the nanoparticles is broken up during high-speed flushing, and the nanoparticles are distributed uniformly in the coating. Therefore, using JED to prepare nanoparticle-reinforced composite coating, the advantages of a high deposition efficiency, uniform nanoparticles distribution, and good quality of the coating can be obtained [8-10].

During electrodeposition, the preferred orientation (texture) often occurs, which means that significant amounts of grains exhibit the same common orientation characteristics in the deposition layer. This is called a highly preferred orientation if almost all of the grains are assembled in one certain orientation. By controlling the preferred orientation of the grains in the deposition layer, the properties of the deposition layer can be improved, and even the deposition layer has some special functions. Gao et al. [11] fabricated Co-Ni films with a preferred (220) orientation by controlling the variation of the $\mathrm{Co}$ and Ni ratio, which showed a superior photocatalytic performance. Ponrouch et al. [12] prepared preferentially oriented (100) platinum nanowires and thin films by changing the deposition potential, which exhibited efficient electrocatalytic properties. Kim et al. [13] manufactured $\mathrm{Bi}_{2} \mathrm{Te}_{3-\mathrm{x}} \mathrm{Se}_{\mathrm{x}}$ thin films using pulse electrodeposition. By changing the duty cycle of the current, thin films achieved a preferred orientation of (110), and displayed a superior thermoelectric performance.

In recent years, research on the preferred orientation of nickel coatings using CED has attracted significant attention. Calderón et al. [14] carried out an experiment on the preparation of $\mathrm{Ni}-\mathrm{SiC}$ composite coatings. It was found that with an increase in the SiC content, the grain orientation of the coatings gradually evolved from (200) to (111), and the corrosion resistance of the coating improved with the grain orientation of (111). Zhao et al. [15] studied Ni-xAl-yTi composite coatings, and claimed that as the content of $\mathrm{Al}$ and $\mathrm{Ti}$ particles increased, the orientation of (200) decreased while (111) increased; in addition, the preferred (111) orientation coating showed a better corrosion resistance than the preferred (200) orientation. Alizadeh et al. [16] conducted an analysis on $\mathrm{Ni}-\mathrm{Cu} / \mathrm{Al}_{2} \mathrm{O}_{3}$ composite coatings. They reported that the structure of the coatings gradually evolved to a preferred (111) orientation when the $\mathrm{Al}_{2} \mathrm{O}_{3}$ content increased, and the hardness, wear resistance, and corrosion resistance of the coatings were improved. Deng et al. [17] demonstrated that with the addition of 1,4-bis(2hydroxyethoxy)-2-butyne (BEO), the grains preferred the orientation of $\mathrm{Ni} /$ diamond composite coatings over a (200) orientation, and the wear resistance of the coating was also enhanced.

The above studies on the preferred orientation of nickel-based composite coatings mainly focused on (111) and (200) orientations, and little research has been conducted on the highly preferred (220) orientation. This paper reveals the efficient preparation of nanoparticlereinforced nickel-based composite coating with a highly preferred (220) orientation, and then explores the effect of the deposition parameters on the structure of nanoparticle-reinforced nickel-based composite coatings. Because of the high hardness and stability of $\mathrm{SiC}$ nanoparticles, $\mathrm{Ni}-\mathrm{SiC}$ composite coatings have been widely used [18]. This paper focused on the properties of $\mathrm{Ni}-\mathrm{SiC}$ composite coatings. The microstructure, corrosion resistance, and the adhesion force of the $\mathrm{Ni}-\mathrm{SiC}$ composite coating with a highly preferred (220) orientation were investigated. Some innovative theoretical and technological achievements were made.

\section{Experiment}

\subsection{Principle of Efficient Preparation of Nanoparticles Reinforced Nickel-Based Composite Coating by JED}

The experimental device for JED is shown in Figure 1a. The pure titanium rod connects to the positive pole of the DC power supply, and the substrate connects to the negative pole of the DC power supply. The pure titanium rod acts as the current transfer electrode, which transfers the current to nickel balls, making the nickel balls become an anode. Nickel atoms are oxidized into a large amount of $\mathrm{Ni}^{2+}$, which is used to supplement the $\mathrm{Ni}^{2+}$ that is constantly consumed during the plating solution. The titanium rod is not consumed in experiments because the chemical properties of the titanium rod are more stable than those of the nickel balls. Because the titanium rod is closer to the upper surface of the substrate, the unconsumed titanium rod can help provide a stable electric field environment, and the deposited coatings achieve a better uniformity. The plating solution in the liquid storage tank is heated by a water bath to maintain a constant temperature. During the preparation process, the composite plating solution is first transported to the anode cylinder through the inlet pipe by a diaphragm pump. The plating solution in the anode cylinder is then impacted on the substrate through the nozzle at a high 


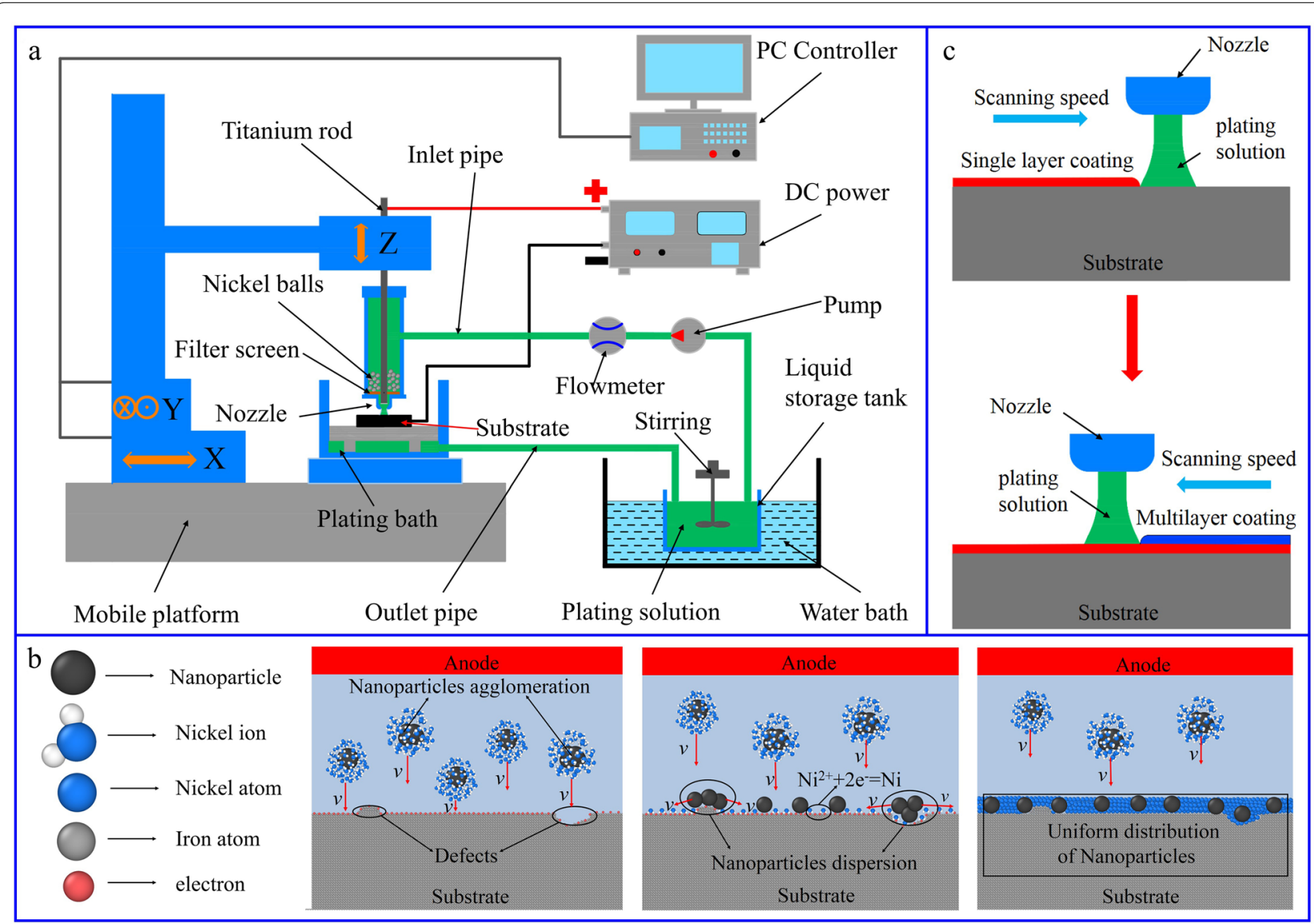

Figure 1 Schematic diagram of a experimental device for JED, b preparation principle of nanoparticle-reinforced nickel-based composite coatings, and $\mathbf{c}$ production process of nanoparticle-reinforced nickel-based composite coatings

speed for deposition. Finally, the plating solution flows back to the liquid storage tank through the outlet pipe.

A schematic diagram of the preparation principle of nanoparticle-reinforced nickel-based composite coatings using JED is illustrated in Figure 1b. Most of the nanoparticles exist in the plating solution as an agglomeration, which is mainly surrounded by water molecules and ion clusters. Because the main chemical reaction is the redox of $\mathrm{Ni}^{2+}$ during electrodeposition, the model is simplified into a nanoparticle agglomeration surrounded by a large number of $\mathrm{Ni}^{2+}$ ions. When the nanoparticle agglomeration is impacted by the substrate at a high speed, the nanoparticle agglomeration is divided into many individual nanoparticles owing to the reacting force. According to the composite co-deposition theory $[19,20]$, some nanoparticles are adsorbed on the substrate, among which the strongly adsorbed nanoparticles are deposited and the weakly adsorbed nanoparticles are washed away. Meanwhile, under the condition of a high deposition current density, a large amount of $\mathrm{Ni}^{2+}$ near the cathode is reduced to $\mathrm{Ni}$ atoms, and then $\mathrm{Ni}$ atoms are then deposited on the substrate. The stacking of $\mathrm{Ni}$ atoms and nanoparticles covering the substrate rapidly becomes defective, and eventually a nanoparticle-reinforced nickel-based composite coating with a smooth surface is formed.

As shown in Figure 1c, the thickness of the coating increases gradually when the nozzle moves back and forth along the path at a certain scanning speed. The required thickness and shape of the composite coating are obtained by controlling the nozzle path and deposition time.

\subsection{Experimental Parameters Applied in the Preparation of Nanoparticle-Reinforced Nickel-Based Composite Coating Using JED}

The composition of the plating solution and the experimental parameters are shown in Table 1 . The purity of the $\mathrm{SiC}$ nanoparticles was $99.99 \%$ and the average particle size was approximately $50 \mathrm{~nm}$ as shown in Figure 2a and $b$. SEM figures are also shown in Figure $2 a$ and $b$. The substrate material was a medium-carbon steel. The 
Table 1 Composition of plating solution and experimental parameters

\begin{tabular}{ll}
\hline Composition and parameters & Quantity \\
\hline $\mathrm{NiSO}_{4} \cdot 6 \mathrm{H}_{2} \mathrm{O}(\mathrm{g} / \mathrm{L})$ & 300 \\
$\mathrm{NiCl}_{2} \cdot 6 \mathrm{H}_{2} \mathrm{O}(\mathrm{g} / \mathrm{L})$ & 40 \\
$\mathrm{H}_{3} \mathrm{BO}_{4}(\mathrm{~g} / \mathrm{L})$ & 40 \\
$\mathrm{Saccharin}(\mathrm{g} / \mathrm{L})$ & 0.5 \\
Emulsifier OP-10 (g/L) & 1.0 \\
$\mathrm{SiC}$ nano-particles $(\mathrm{g} / \mathrm{L})$ & 3.0 \\
$\mathrm{pH}$ value & 4.0 \\
Nozzle diameter $(\mathrm{mm})$ & 5.0 \\
Scanning speed of nozzle (mm/min) & 100 \\
Distance between nozzle and cathode $(\mathrm{mm})$ & 3.0 \\
Injection velocity $(\mathrm{m} / \mathrm{s})$ & $1.40-2.65$ \\
Current density $\left(\mathrm{A} / \mathrm{dm}^{2}\right)$ & $180-220$ \\
Temperature $\left({ }^{\circ} \mathrm{C}\right)$ & 60 \\
\hline
\end{tabular}

substrate was pretreated before the experiment, the process of which is as follows: fine grinding, - oil removal, acetone ultrasonic cleaning, - alcohol ultrasonic cleaning, - deionized water ultrasonic cleaning, - and drying. An XRD pattern of the substrate is shown in Figure 2c.

\subsection{Test details}

The grain orientation and grain size of the nanoparticlereinforced nickel-based composite coatings were characterized using X-ray diffraction (XRD, X'Pert Pro MPD) with $\mathrm{Cu}-\mathrm{K} \alpha(\lambda=0.154184 \mathrm{~nm})$ radiation, and the test parameters were a voltage of $45 \mathrm{kV}$, current of $40 \mathrm{~mA}$, scanning range of $20^{\circ}$ to $90^{\circ}$, step width of $0.01^{\circ}$, and scanning speed of $10^{\circ} / \mathrm{min}$. The adhesion force of the nanoparticle-reinforced nickel-based composite coatings were quantitatively texted using a scratch tester (WS2004). The test was carried out in the form of dynamic loading. The scratch length was $4 \mathrm{~mm}$, and the diamond tool was uniformly loaded from 0 to $70 \mathrm{~N}$ at a loading
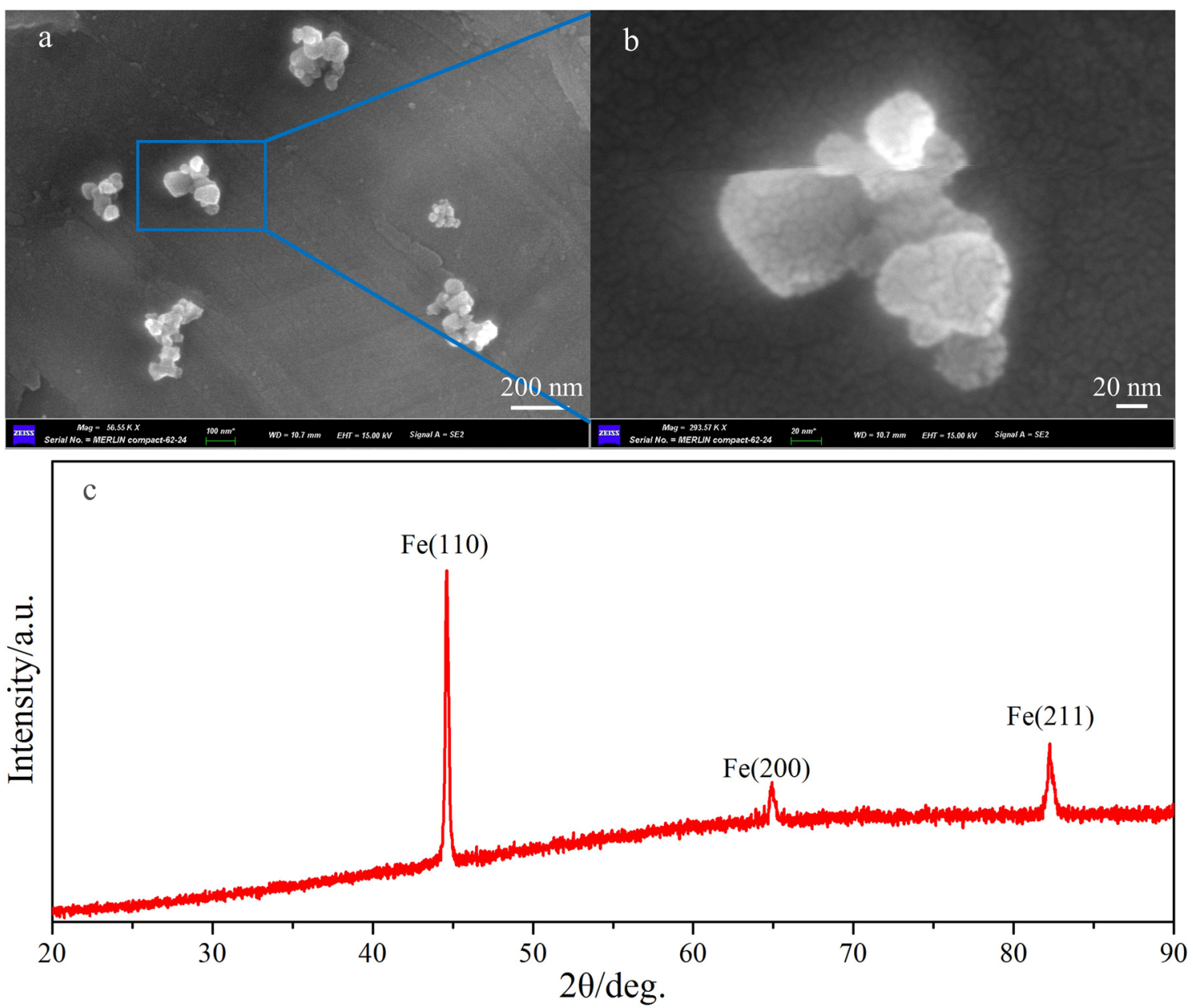

Figure 2 The morphology and composition of SiC nanoparticles: a SEM image, $\mathbf{b}$ enlarged image, $\mathbf{c}$ XRD pattern of substrate 
rate of $70 / 4 \mathrm{~N} / \mathrm{mm}$. The morphology and elemental content of the nanoparticle-reinforced nickel-based composite coatings were measured using scanning electron microscopy with energy dispersive spectroscopy (SEM, EDS, ZEISS MERLIN Compact). The surface roughness of nanoparticle-reinforced nickel-based composite coatings were measured using TR300 Roughness Measuring Instrument with a sampling length of $4 \mathrm{~mm}$. The electrochemical properties of the $\mathrm{Ni}-\mathrm{SiC}$ composite coatings were evaluated using electrochemical workstation (CHI $760 \mathrm{e})$ in a $3.5 \mathrm{wt} \% \mathrm{NaCl}$ solution at room temperature. The test samples were $\mathrm{Ni}-\mathrm{SiC}$ composite coatings with an area of $1 \mathrm{~cm}^{2}$. A saturated calomel electrode, platinum plate and samples were used as the reference electrode, counter electrode and working electrode, respectively. The polarization curves were recorded within the potential range of -150 to $+350 \mathrm{mV}$ (compared to the Eocp) at a scan rate of $0.002 \mathrm{~V} / \mathrm{s}$ and a scan frequency of $2 \mathrm{~Hz}$. Electrochemical impedance spectroscopy (EIS) investigations were conducted at sinusoidal signal amplitude of $10 \mathrm{mV}$ and at a frequency range of $10^{5}$ to $10^{-2} \mathrm{~Hz}$. Full immersion corrosion tests of the $\mathrm{Ni}-\mathrm{SiC}$ composite coatings are carried out. The corrosion solution was a $3.5 \mathrm{wt} \%$ $\mathrm{NaCl}$ solution, and the corrosion time were $1,3,5$, and 10 days.

\section{Results and Discussion}

\subsection{Grain Orientation Evolution of Ni-SiC Composite Coating during JED}

During the JED process, the deposition layer is rapidly formed on the surface of the substrate under the condition of high current density by means of high-speed jetting. Therefore, the injection velocity and current density are important parameters influencing the structure of the coatings. In this study, a large number of $\mathrm{Ni}-\mathrm{SiC}$ composite coatings were one produced at different current densities and injection velocities. The thicknesses of these coatings were controlled to approximately $50 \mu \mathrm{m}$ by changing the deposition time. According to Figure 3a-e, the XRD patterns of the $\mathrm{Ni}-\mathrm{SiC}$ composite coatings prepared using JED under different deposition parameters all present clear diffraction peaks of $\mathrm{Ni}(111), \mathrm{Ni}(200)$, and $\mathrm{Ni}(220)$. It can be seen that with an increase in the deposition current density from $180 \mathrm{~A} / \mathrm{dm}^{2}$ to $220 \mathrm{~A} / \mathrm{dm}^{2}$, the coating orientation shows a trend of gradual evolution to $\mathrm{Ni}(220)$. The XRD pattern of the Ni-SiC composite coating prepared using CED is shown in Figure 3f, which indicates a $\mathrm{Ni}$-SiC composite coating without a highly preferred (220) orientation.

The preferred orientation coefficient (texture coefficients) of different crystal planes in these coatings are calculated using Eq. (1) [21], where TC(hkl) is the texture coefficient of the (hkl) orientation, I(hkl) is the measured intensity of (hkl) reflection, I0(hkl) is the powder diffraction intensity of nickel (PDF\#70-0989), and $\mathrm{n}$ is the number of reflections used in the calculations. In this case, (111), (200) and (220) peaks were used for the texture coefficient calculation $(n=3)$.

$$
\mathrm{TC}(\mathrm{hkl})=\frac{I_{(\mathrm{hkl})} / I_{0(\mathrm{hkl})}}{\sum_{i=1}^{n} I_{(\mathrm{hkl})} / I_{0(\mathrm{hkl})}}
$$

The grain sizes of these coatings are calculated using Eq. (2) [22], where $\mathrm{D}(\mathrm{hkl})$ represents the grain size of the (hkl) orientation, B represents the half-height width of diffraction peak (degree), $\gamma$ represents the wavelength of $\mathrm{Cu}-\mathrm{K} \alpha(\lambda=0.154184 \mathrm{~nm}), \theta$ is the Bragg angle (rad) and $K$ is a constant $(K=0.89)$.

$$
\mathrm{D}(\mathrm{hkl})=\frac{K \gamma}{B \cos \theta} .
$$

Figure $4 a-c$ shows the variations in TC (111), TC (200), and $\mathrm{TC}(220)$ of $\mathrm{Ni}-\mathrm{SiC}$ composite coatings prepared using JED under different deposition parameters. When the current density increases, it shows a general trend in which TC(111) and TC(200) gradually decreases and TC (220) gradually increases. Under low current density conditions (180-200 A/dm ${ }^{2}$ ), the TC (111), TC (200) and $\mathrm{TC}(220)$ are significantly affected by variations in the injection velocity. As the injection velocity increased, TC (111) and TC(200) first decreased and then increased, and TC(220) first increased and then decreased. However, at a higher deposition current density ( $>200 \mathrm{~A} /$ $\mathrm{dm}^{2}$ ), the grain orientation of the coatings is slightly affected by the variation of the injection velocity, and TC (111), TC (200) and TC (220) remain stable. Under the deposition conditions of $220 \mathrm{~A} / \mathrm{dm}^{2}$ current density and $1.76 \mathrm{~m} / \mathrm{s}$ injection velocity, TC (220) reached a maximum of $97.7 \%$.

As shown in Figure 4d, it can be seen that the variation range of $\mathrm{D}(111)$ and $\mathrm{D}(200)$ is small as the current density increases. The value of $\mathrm{D}(111)$ is between 19 and 20 $\mathrm{nm}$ and $\mathrm{D}(200)$ is between 17 and $18 \mathrm{~nm}$. Unlike $\mathrm{D}(111)$ and $\mathrm{D}(200), \mathrm{D}(220)$ increases with an increase in the deposition current density. When the deposition current density is $180 \mathrm{~A} / \mathrm{dm}^{2}$, the average value of $\mathrm{D}(220)$ is 47.5 $\mathrm{nm}$. As the deposition current density increase to $220 \mathrm{~A} /$ $\mathrm{dm}^{2}$, the average value of $\mathrm{D}(220)$ increase to $61.6 \mathrm{~nm}$.

As shown in Figure 5, during the preparation of nanoparticle-reinforced nickel-based composite coatings using JED, Ni atoms are stacked with face-centered cubic structure cells. Usually, these cells are deposited on the substrate surface with the (111), (200), and (220) crystalline planes. The selection of the grain orientation mainly depends on the cathodic overpotential, which is mainly 


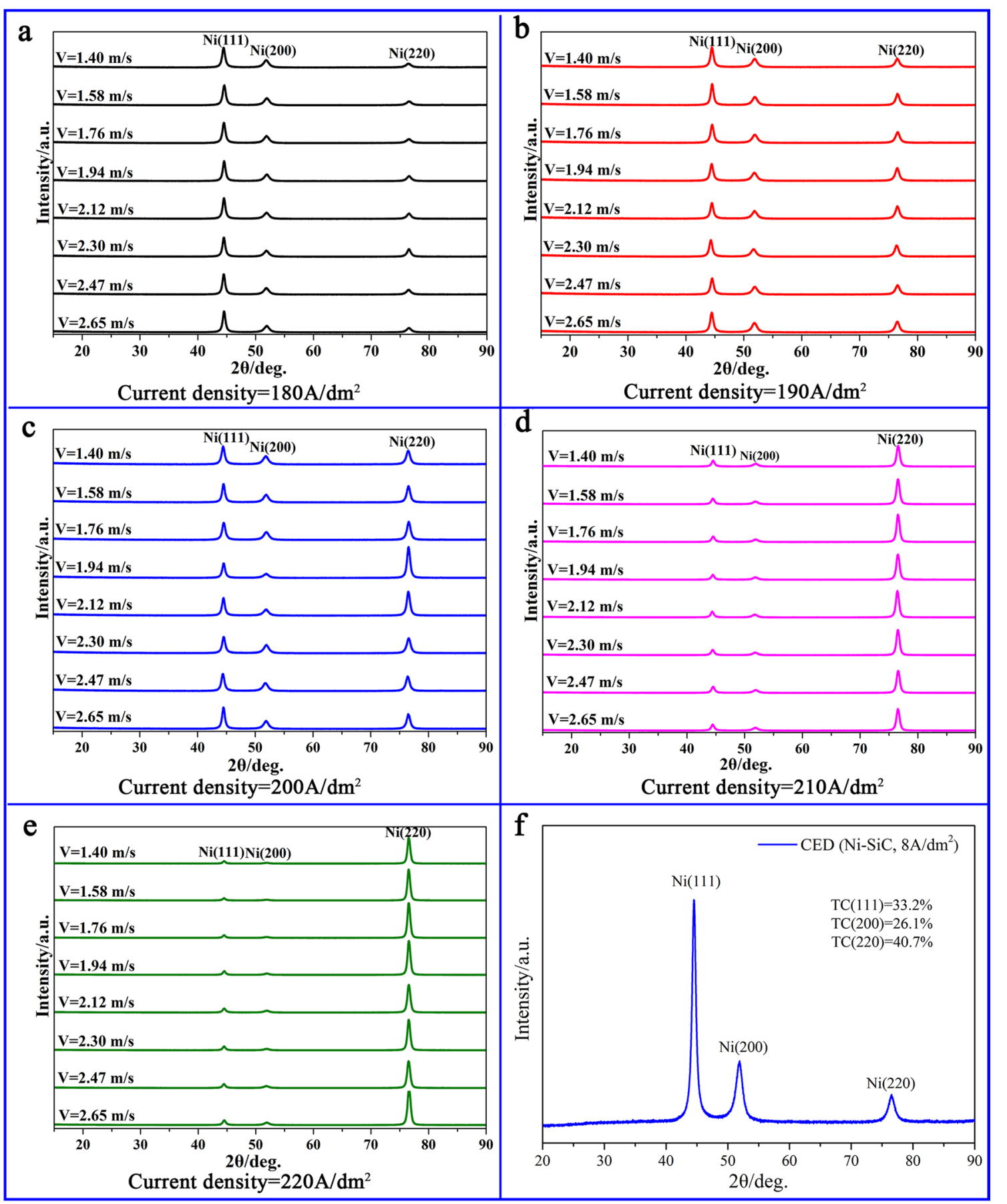

Figure 3 a-e XRD patterns of Ni-SiC composite coatings prepared using JED under different deposition parameters, and $\mathbf{f}$ XRD pattern of Ni-SiC composite coating prepared using CED

based on the deposition current density according to the Tafel formula. Under the condition of a low deposition current density, the grain orientation of coating tends to be (111). As the deposition current density increases the grain orientation of the coating gradually evolves to
(220). When the deposition current density exceeds a certain value, most of the cells are adsorbed on the substrate with the (220) crystalline plane.

Compared with the influence of the deposition current density, the effect of the injection velocity on the grain 


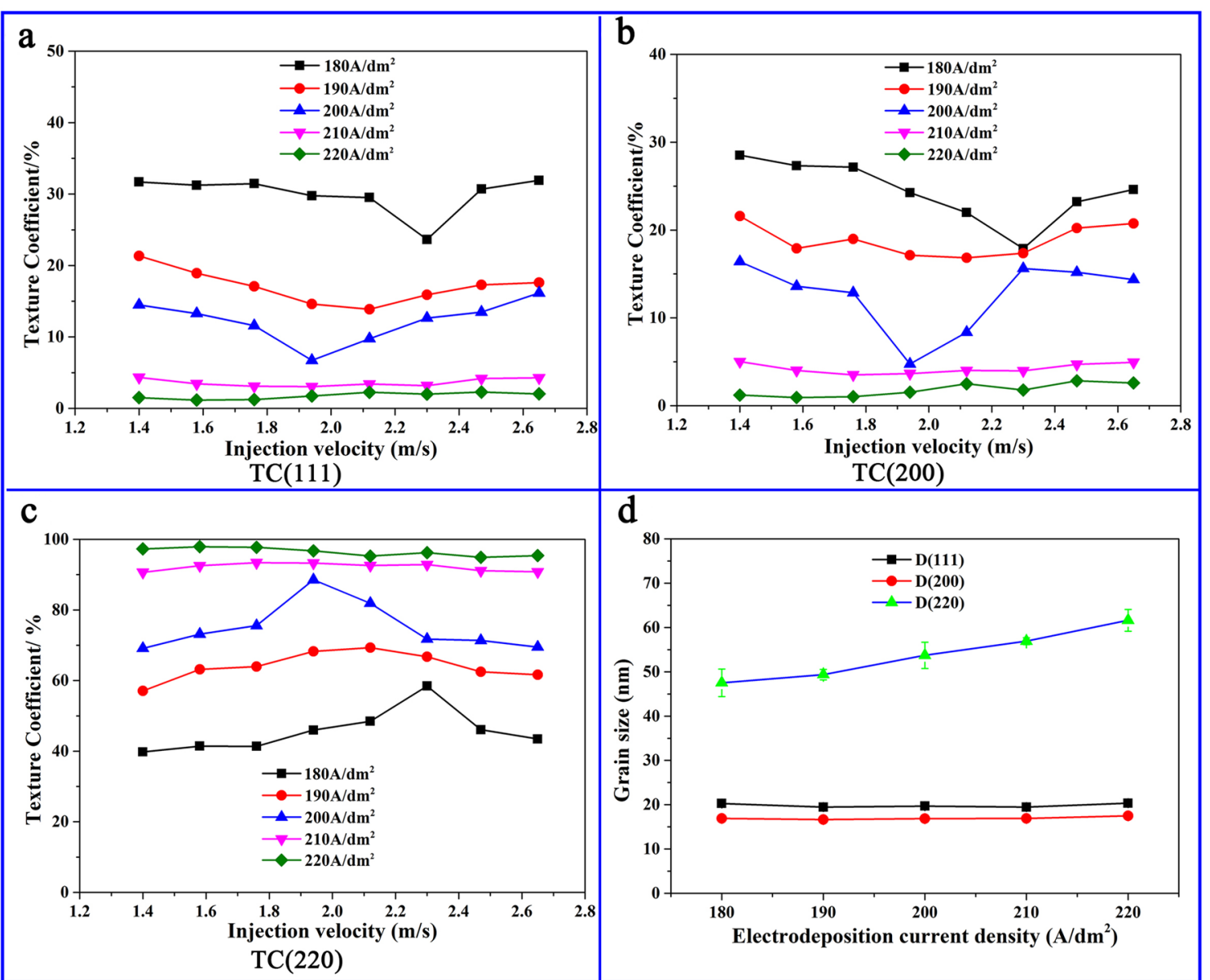

Figure 4 a-c The texture coefficients of Ni-SiC composite coatings prepared using JED under different deposition parameters: a TC(111), b TC(200), and $\mathbf{c T C}(220)$; $\mathbf{d}$ The grain size statistic of Ni-SiC composite coatings prepared using JED under different deposition parameters

orientation of the coating is smaller. Because the bonding strength of the (111) - and (200) - oriented grains to the substrate is less than that of the (220) - oriented grains, the increase in the injection velocity tends to makes the nickel structure cells adsorb into the substrate with the (220) crystalline plane. However, the TC(220) of the coating does not increase monotonically with an increase in the injection velocity. There is a critical value for the injection speed. When the injection speed exceeds this value, the nickel structure cells tend to adsorb into the substrate with random crystalline planes instead. The critical value has a negative correlation with the density of deposition current, that is, the smaller the deposition current density is, the larger the critical value.

Under the condition of a high deposition current density, the nickel structure cells rapidly nucleate, and the number of crystal nuclei with a (220) orientation is larger than that with (111) and (200) orientations. Therefore, the crystal nucleus with the (220) orientation dominates the growth process. Eventually, the average size of the
(220) orientation grains is clearly larger than that of the (111) and (200) orientation grains.

\subsection{Morphology of Ni-SiC Composite Coating with Highly Preferred (220) Orientation}

Figure 6 shows the morphology of a $\mathrm{Ni}-\mathrm{SiC}$ composite coating with a highly preferred (220) orientation prepared using JED $(\mathrm{TC}(220)=97.7 \%)$. As shown in Figure 6a, the surface (Area $\mathrm{C}$ ) and section (Area F) of the coating were observed. It is clear that the surface of the $\mathrm{Ni} \mathrm{SiC}$ composite coating with a highly preferred (220) orientation is compact and flat (Figure $6 \mathrm{c}, \mathrm{f}$ ), and there is no dome or hill/ valley-like structure [16, 23-25]. The surface roughness of the coating was $R_{\mathrm{a}} 0.119 \mu \mathrm{m}$ (Figure $6 \mathrm{~b}) . \mathrm{SiC}$ nanoparticles had no agglomeration inside the coating (Figure $6 \mathrm{~d}, \mathrm{~g}$ ) and were evenly distributed in different areas of the coating (Figure 6e, h).

Figure 7 shows the morphology of a $\mathrm{Ni}-\mathrm{SiC}$ composite coating without a highly preferred (220) orientation prepared using JED $(\mathrm{TC}(220)=41.4 \%)$. As shown in 


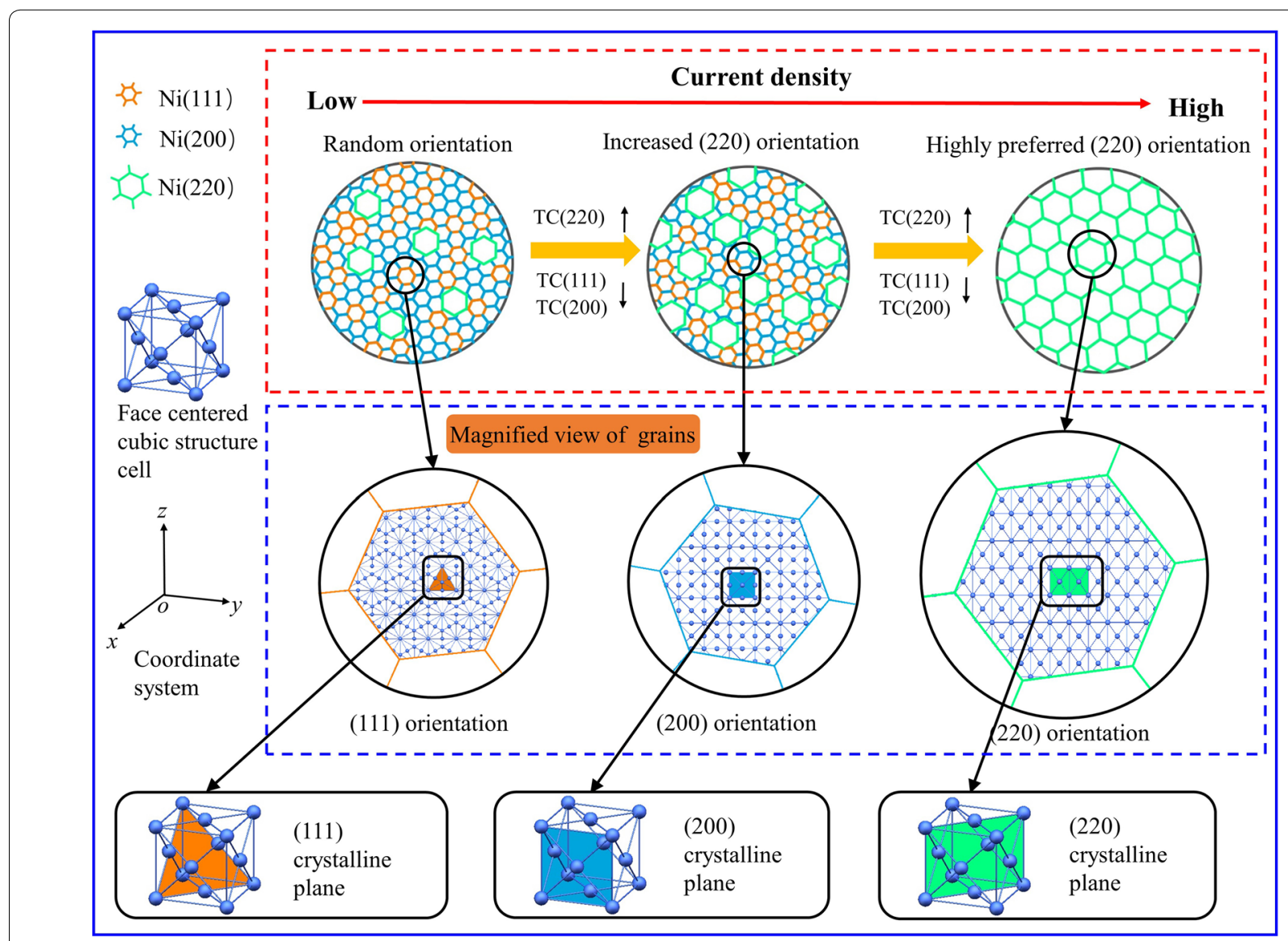

Figure 5 Schematic diagram of the evolution of grain orientation during the process of preparing nanoparticle-reinforced nickel-based composite coatings using JED

Figure 7a, the surface (Area C) and section (Area F) of the coating were observed. It is clear that the surface of the $\mathrm{Ni} \mathrm{SiC} \mathrm{composite} \mathrm{coating} \mathrm{has} \mathrm{slight} \mathrm{bumps} \mathrm{and} \mathrm{gul-}$ lies. The surface roughness of the coating was $R_{\mathrm{a}} 0.321$ $\mu \mathrm{m}$ (Figure $7 \mathrm{~b}$ ). $\mathrm{SiC}$ nanoparticles have no agglomeration inside the coating (Figure $7 \mathrm{~d}, \mathrm{~g}$ ) and were evenly distributed in different areas of the coating (Figure 7e, h).

Figure 8 shows the morphology of a $\mathrm{Ni}-\mathrm{SiC}$ composite coating prepared using CED $(\mathrm{TC}(220)=40.7 \%)$. As shown in Figure 8a, the surface (Area $\mathrm{C}$ ) and section (Area F) of the coating were also observed. The surface of the $\mathrm{Ni} \mathrm{SiC} \mathrm{composite} \mathrm{coating} \mathrm{prepared} \mathrm{by} \mathrm{CED} \mathrm{is} \mathrm{coarse}$ and fluctuant (Figure 8c, f). The surface roughness of the coating was $R_{\mathrm{a}} 1.210 \mu \mathrm{m}$ (Figure $8 \mathrm{~b}$ ). SiC nanoparticles have an obvious agglomeration inside the coating (Figure $8 \mathrm{~d}, \mathrm{~g}$ ) and the content varies greatly in different areas (Figure 8e, h).

Compared with the coating prepared using CED, The high-speed jetting process used by JED can make $\mathrm{SiC}$ nanoparticles evenly distributed in the coating and the surface quality of the coating prepared through JED is obviously improved owing to the high-speed scouring of the plating solution. For the JED, the Ni-SiC composite coating with a highly preferred (220) orientation has a smoother surface topography, which is beneficial for significantly improve the corrosion resistance of the $\mathrm{Ni}-\mathrm{SiC}$ composite coating.

\subsection{Corrosion Resistance of Ni-SiC Composite Coating with Highly Preferred (220) Orientation}

In this study, the corrosion resistance of the $\mathrm{Ni}-\mathrm{SiC}$ composite coating was tested, including electrochemical tests and full immersion corrosion tests. Figure 9 shows the electrochemical test results of the $\mathrm{Ni}-\mathrm{SiC}$ composite coatings in a $3.5 \mathrm{wt} \% \mathrm{NaCl}$ solution. The dynamic polarization curves are shown in Figure 9a. As can be seen from this figure, the corrosion potential $\left(E_{\text {corr }}\right)$ and corrosion current density $\left(i_{\text {corr }}\right)$ of the $\mathrm{Ni}-\mathrm{SiC}$ composite coating prepared using CED were $-0.747 \mathrm{~V}$ and $54.52 \mu \mathrm{A} / \mathrm{cm}^{2}$, respectively.

The $\mathrm{Ni}-\mathrm{SiC}$ composite coatings were prepared using JED at an injection velocity of $1.76 \mathrm{~m} / \mathrm{s}$ and a 

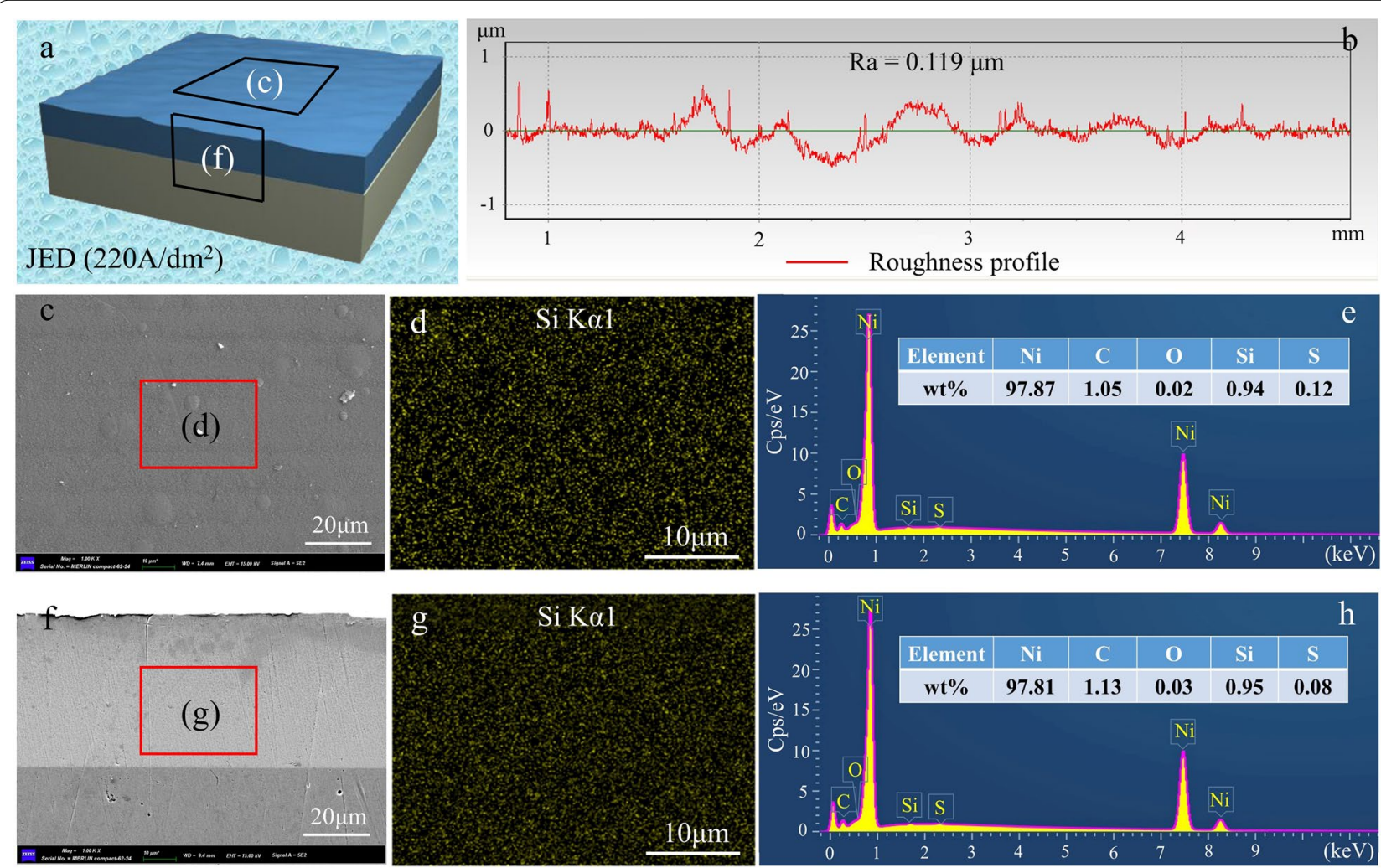

Figure 6 Morphology of the Ni-SiC composite coating with highly preferred (220) orientation prepared using JED: a schematic diagram of detection area, $\mathbf{b}$ roughness profile of the coating surface, $\mathbf{c}$ microstructure of the coating surface, $\mathbf{d}$ distribution of SiC nanoparticles on the coating surface, e EDS map of the coating surface, $\mathbf{f}$ microstructure of the coating section, $\mathbf{g}$ distribution of SiC nanoparticles on the coating section, and $\mathbf{h}$ EDS map of the coating section

current density of $180-220 \mathrm{~A} / \mathrm{dm}^{2}$. With an increase in the deposition current density, the $\mathrm{TC}(220)$ of the coating increases from $41.4 \%$ to $97.7 \%$, the corrosion potential of the coating increased from -0.575 to $-0.477 \mathrm{~V}$, and the corrosion current density decreased from 9.52 to $2.76 \mu \mathrm{A} / \mathrm{cm}^{2}$. This indicates that the corrosion resistance of the coating was enhanced. EIS is a powerful and nondestructive electrochemical technology to confirm electrochemical reactions and study the corrosion behavior of electrode/electrolyte interface [26-29]. Figure 9b shows the typical Nyquist plots of the $\mathrm{Ni}-\mathrm{SiC}$ composite coatings. A depressive semicircle can be found on each curve, indicating that the electrochemical mechanism is controlled by the charge-transfer process [30]. It can be seen that the diameter of the capacitive loop increases with an increase in $\mathrm{TC}(220)$ of the $\mathrm{Ni}-\mathrm{SiC}$ composite coating. A larger diameter of the capacitive loop, results in a stronger corrosion resistance of the coating. Figure $9 \mathrm{c}$ shows the Bode plots of $\log (\mathrm{f})$ versus $\log (|\mathrm{Z}|)$ of the Ni-SiC composite coatings. Within the high-frequency region $\left(10^{4}\right.$ to $\left.10^{5} \mathrm{~Hz}\right)$, the values of $\log |\mathrm{Z}|$ are similar, indicating that these are impedance values of a
$3.5 \mathrm{wt} \% \mathrm{NaCl}$ solution. Within the low-frequency region $\left(10^{-2}\right.$ to $\left.10^{-1} \mathrm{~Hz}\right)$, the impedance values of the different $\mathrm{Ni}-\mathrm{SiC}$ composite coatings are significantly different. For instance, at a fixed $0.01 \mathrm{~Hz}$, the $\log (|\mathrm{Z}|)$ of the $\mathrm{Ni}$-SiC composite coating prepared using CED is 3.41, and the $\log (|\mathrm{Z}|)$ of $\mathrm{Ni}-\mathrm{SiC}$ composite coating prepared by JED increase from 3.99 to 4.72 as $\mathrm{TC}(220)$ increase from $41.4 \%$ to $97.7 \%$. The higher the impedance value is, the stronger the corrosion resistance of the coating. Figure 9d shows the Bode plots of $\log (\mathrm{f})$ versus angle of the $\mathrm{Ni}-\mathrm{SiC}$ composite coatings. For the $\mathrm{Ni}-\mathrm{SiC}$ composite coatings, the higher phase angle at the middle high frequency for the chemical-conversion-treated specimen corresponds to a capacitive behavior, that is, the conversion coating has good dielectric properties to avoid the ionic flow of the electrolyte [30]. When the frequency is in the range of $10^{0}$ to $10^{5} \mathrm{~Hz}$, the phase angle of the $\mathrm{Ni}$ $\mathrm{SiC}$ composite coating prepared using CED is minimum, and the phase angle of the $\mathrm{Ni}-\mathrm{SiC}$ composite coating prepared using JED increases with an increase in TC(220).

The EIS data were fitted using an electrical equivalent circuit (EEC). The corrosion process of the $\mathrm{Ni}-\mathrm{SiC}$ 

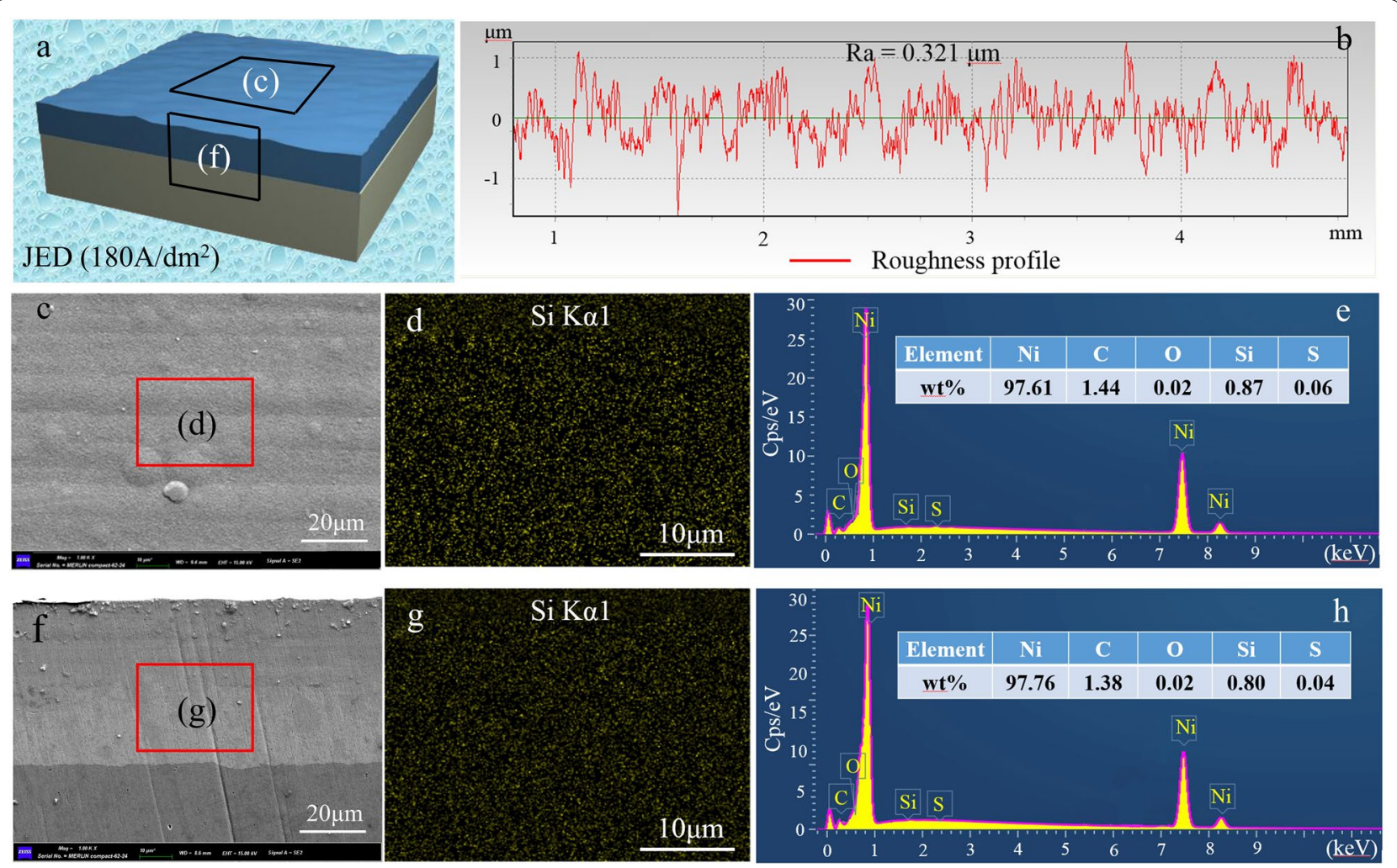

Figure 7 Morphology of the Ni-SiC composite coating without highly preferred (220) orientation prepared using JED: a schematic diagram of detection area, $\mathbf{b}$ roughness profile of the coating surface, $\mathbf{c}$ microstructure of the coating surface, $\mathbf{d}$ distribution of SiC nanoparticles on the coating surface, e EDS map of the coating surface, $\mathbf{f}$ microstructure of the coating section, $\mathbf{g}$ distribution of SiC nanoparticles on the coating section, and $\mathbf{h}$ EDS map of the coating section

composite coating can be replaced with the EEC of $\mathrm{R}(\mathrm{Q}(\mathrm{R}(\mathrm{QR})))$ when the oxide layer on the substrate surface is taken into account [31].

As observed in Figure 9e, the EEC consists of the $R_{\mathrm{s}}$ modeling of the solution resistance, in sequence with a constant phase element $\mathrm{CPE}_{1}$ in parallel with another resistance $R_{\mathrm{c}}$ modeling the coating resistance, followed by another constant phase element $\mathrm{CPE}_{2}$ and a third charge transfer resistance of $R_{\mathrm{ct}}$ associated with the corrosion process. The impedance of the CPE is defined through Eq. (3):

$$
Q_{C P E}=\left[Y_{0}(j \omega)^{n}\right]^{-1},
$$

where $\omega$ is the angular frequency $(\mathrm{rad} / \mathrm{s}), Y_{0}$ is the CPE admittance, $\mathrm{j}$ is the imaginary number $(\sqrt{-1})$, and $n$ with a value of $0-1$ represents the relaxation dispersion. When $n=1$, the CPE is a pure capacitor with a capacitance of $Y_{0}$. It is believed that the smaller the $n$ value is, the more defects that will occur on the surface and the more likely pitting corrosion is to occur [30,32].
The fitting results are listed in Table 2. It can be seen that $R_{\mathrm{c}}$ and $R_{\mathrm{ct}}$ of the $\mathrm{Ni}-\mathrm{SiC}$ composite coating prepared using CED are $1.476 \times 10^{2} \Omega \cdot \mathrm{cm}^{2}$ and $3.846 \times 10^{3} \Omega \cdot \mathrm{cm}^{2}$, respectively. Compared with that of other coatings, these parameters ae the minimum values, which means that this coating has the worst corrosion resistance. The Ni$\mathrm{SiC}$ composite coatings prepared using JED with TC(220) increased from $41.4 \%$ to $97.7 \%$, the $R_{\mathrm{c}}$ of the coatings increased from $4.423 \times 10^{3}$ to $7.025 \times 10^{3} \Omega \cdot \mathrm{cm}^{2}$, and the $R_{\mathrm{ct}}$ increased from $1.267 \times 10^{4}$ to $5.989 \times 10^{4} \Omega \cdot \mathrm{cm}^{2}$ It was proved that the corrosion resistance of the $\mathrm{Ni}-\mathrm{SiC}$ composite coating increased with an increase in $\mathrm{TC}(220)$.

The central area of the coatings after immersion corrosion is observed, and the surface morphologies of different corrosion times are shown in Figures 10, 11, 12 and 13.

It is obvious that when the corrosion time is 1,3 , or 5 days, the central area of the different coatings was mostly unchanged, indicating that the corrosion did not extend to the central area. When the corrosion time was 10 days, 

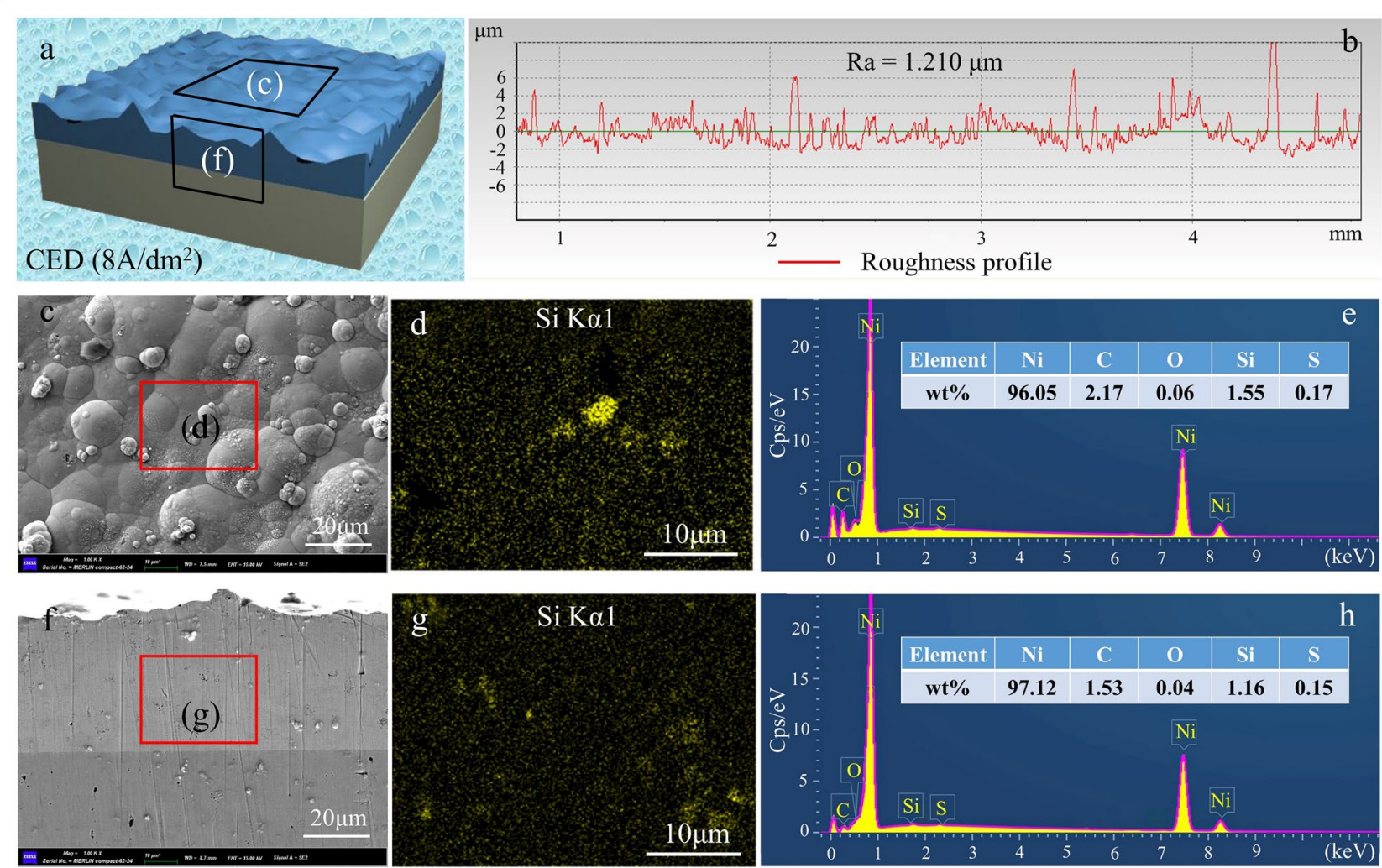

Figure 8 Morphology of the Ni-SiC composite prepared using CED: a schematic diagram of detection area, $\mathbf{b}$ roughness profile of the coating surface, $\mathbf{c}$ microstructure of the coating surface, $\mathbf{d}$ distribution of SiC nanoparticles on the coating surface, e EDS map of the coating surface, $\mathbf{f}$ microstructure of the coating section, $\mathbf{g}$ distribution of SiC nanoparticles on the coating section, and $\mathbf{h}$ EDS map of the coating section

corrosion pits of different sizes appeared on the central surface of the coatings. Figure 13a shows the surface morphology of the Ni-SiC composite coating prepared using CED after 10 days of immersion corrosion. It can be seen that many corrosion products adhere to the surface of the coating, and the size of the corrosion pits is approximately $3.3-22.2 \mu \mathrm{m}$. Figure $13 \mathrm{~b}-\mathrm{f}$ are the surface morphologies of $\mathrm{Ni}-\mathrm{SiC}$ composite coatings prepared using JED after 10 days of immersion corrosion. Compared with Figure 13a, there are no obvious corrosion products on the surface of the coating, and the corrosion pits are all less than $1 \mu \mathrm{m}$. When the $\mathrm{TC}(220)$ of the coating was $41.4 \%$, the size of the corrosion pits was approximately 278-944 nm (Figure 13b). When the TC(220) of the coating was $63.9 \%$, the size of the corrosion pits was approximately $254-927 \mathrm{~nm}$ (Figure 13c). When the $\mathrm{TC}(220)$ of the coating was $75.6 \%$, the size of the corrosion pits was approximately 215-905 nm (Figure 13d). When the $\mathrm{TC}(220)$ of the coating was $93.4 \%$, the size of the corrosion pits was approximately $183-352 \mathrm{~nm}$ (Figure 13e). Finally, when the $\mathrm{TC}(220)$ of the coating was $97.7 \%$, the size of the corrosion pits was approximately $153-260 \mathrm{~nm}$ (Figure 13f). This shows that as the TC(220) increases, the corrosion resistance of the $\mathrm{Ni}-\mathrm{SiC}$ composite coating is improved.

The surface quality is the most important factor affecting the corrosion resistance of the coating. The corrosion resistance of the coating decreases with an increase in the number of surface defects. There are many defects on the surface of $\mathrm{Ni}-\mathrm{SiC}$ composite coating prepared using CED, such as the agglomeration of the $\mathrm{SiC}$ nanoparticles, pinholes and pockmarks. Corrosion occurs preferentially at these defect locations, and over a period of time, it is easy to cause $\mathrm{SiC}$ agglomerated particles to fall off, resulting in the formation of holes in the coating, which eventually form larger corrosion pits with the increase in corrosion time. The surfaces of the $\mathrm{Ni}-\mathrm{SiC}$ composite coatings prepared using JED are compact and flat without obvious defects and $\mathrm{SiC}$ particle agglomeration; thus, the corrosion resistance of the coatings is significantly improved. The corrosion pits occur uniformly at the grain boundaries on the coating surface, and the corrosion pits gradually expand with the increase in corrosion time. Under the same corrosion area, the smaller the grain boundary proportion and the smaller the number 

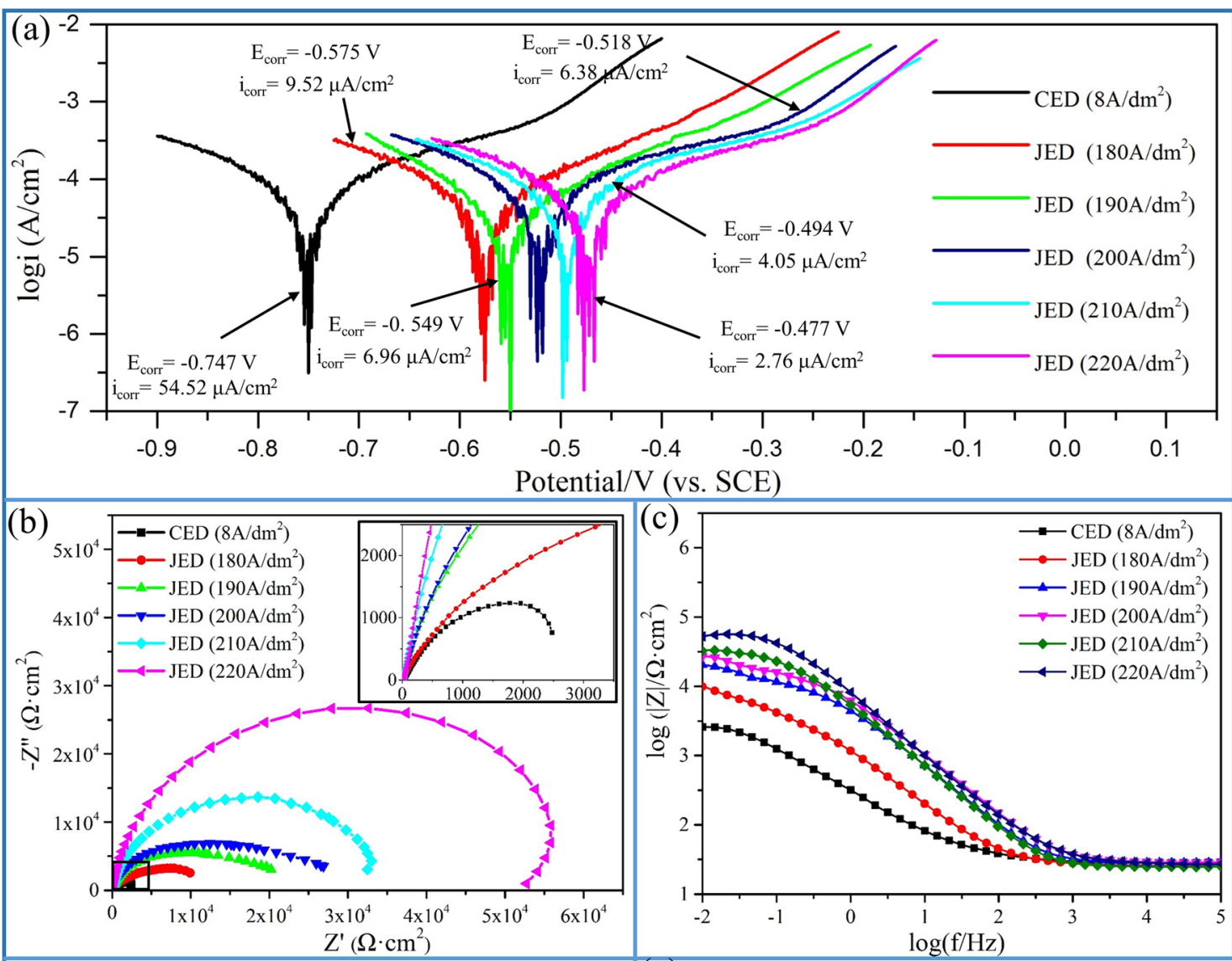

(d)
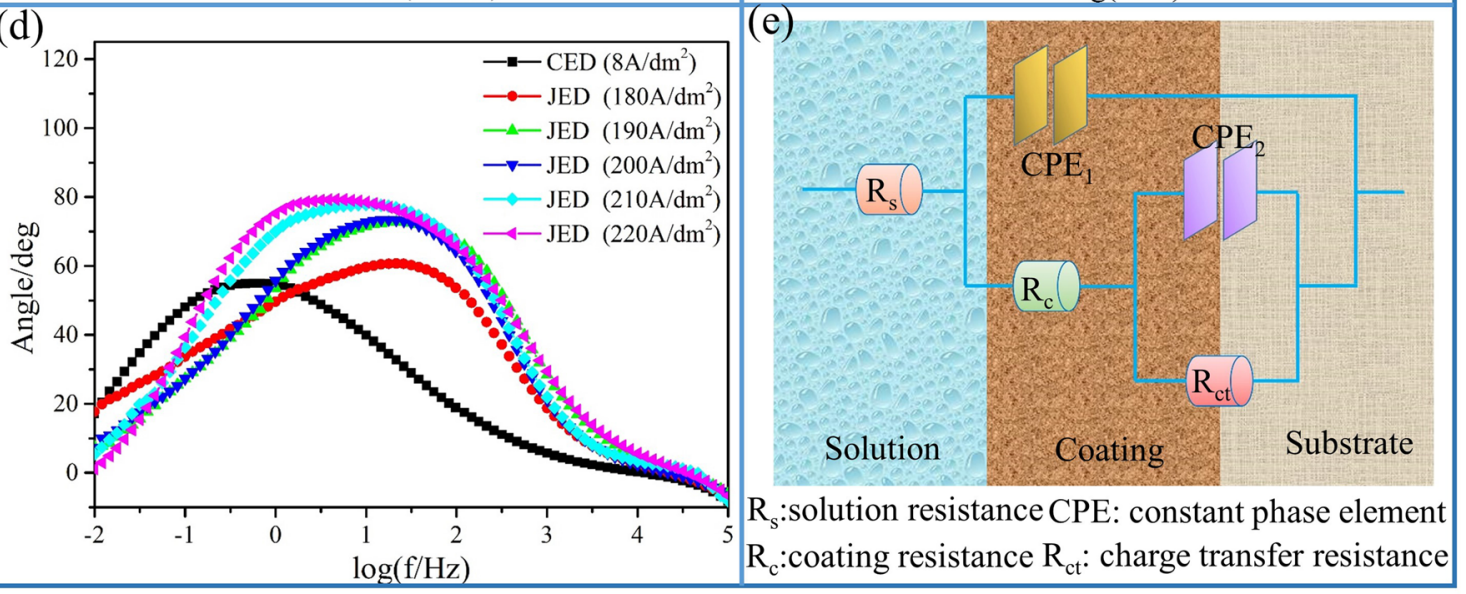

Figure 9 Electrochemical test results of Ni-SiC composite coatings: a dynamic polarization curves, $\mathbf{b}$ Nyquist plots, $\mathbf{c}$ Bode plots of log(f) versus $\log (|Z|), \mathbf{d}$ Bode plots of $\log (f)$ versus the angle, and e schematic diagram of the EEC

of corrosion pits. As the deposition current density increased, the grain size of the $\mathrm{Ni}-\mathrm{SiC}$ composite coating also increased, and the proportion of grain boundaries decreased. At the same time, with the increase in $\mathrm{TC}(220)$, the coating with the same orientation gradually formed. The dislocations and other defects at the grain boundaries also reduced and the diffusion rate of corrosion pits is reduced. Therefore, the $\mathrm{Ni}-\mathrm{SiC}$ coating with a highly preferred (220) orientation shows an excellent corrosion resistance. 
Table 2 Parameters fitted from EEC

\begin{tabular}{|c|c|c|c|c|c|c|c|c|}
\hline \multirow{2}{*}{$\begin{array}{l}\text { Preparation } \\
\text { method }\end{array}$} & \multirow{2}{*}{$\begin{array}{l}\mathrm{TC}(220) \\
(\%)\end{array}$} & \multirow{2}{*}{$\begin{array}{l}R_{\mathrm{s}} \\
\left(\Omega \cdot \mathrm{cm}^{2}\right)\end{array}$} & \multicolumn{2}{|l|}{$\mathrm{CPE}_{1}$} & \multirow{2}{*}{$\begin{array}{l}R_{\mathrm{c}} \\
\left(\Omega \cdot \mathrm{cm}^{2}\right)\end{array}$} & \multicolumn{2}{|l|}{$\mathrm{CPE}_{2}$} & \multirow{2}{*}{$\begin{array}{l}R_{\mathrm{ct}} \\
\left(\Omega \cdot \mathrm{cm}^{2}\right)\end{array}$} \\
\hline & & & $Y_{1}\left(\mathrm{~S} \cdot \mathrm{cm}^{-2} \cdot \mathrm{s}^{\mathrm{n}}\right)$ & $n_{1}$ & & $Y_{2}\left(\mathrm{~S} \cdot \mathrm{cm}^{-2} \cdot \mathrm{s}^{\mathrm{n}}\right)$ & $n_{1}$ & \\
\hline CED $\left(8 \mathrm{~A} / \mathrm{dm}^{2}\right)$ & 40.7 & 28.37 & $8.579 \times 10^{-4}$ & 0.6753 & $1.476 \times 10^{2}$ & $8.759 \times 10^{-4}$ & 0.6846 & $3.846 \times 10^{3}$ \\
\hline$J E D\left(180 \mathrm{~A} / \mathrm{dm}^{2}\right)$ & 41.4 & 25.83 & $1.661 \times 10^{-4}$ & 0.5643 & $4.423 \times 10^{3}$ & $1.658 \times 10^{-4}$ & 0.5635 & $1.267 \times 10^{4}$ \\
\hline $\mathrm{JED}\left(190 \mathrm{~A} / \mathrm{dm}^{2}\right)$ & 63.9 & 28.32 & $3.686 \times 10^{-5}$ & 0.8795 & $1.159 \times 10^{3}$ & $4.880 \times 10^{-5}$ & 0.5677 & $2.119 \times 10^{4}$ \\
\hline$J \operatorname{JED}\left(200 \mathrm{~A} / \mathrm{dm}^{2}\right)$ & 75.6 & 28.83 & $2.588 \times 10^{-5}$ & 0.8722 & $1.571 \times 10^{3}$ & $3.386 \times 10^{-4}$ & 0.6184 & $2.608 \times 10^{4}$ \\
\hline $\operatorname{JED}\left(210 \mathrm{~A} / \mathrm{dm}^{2}\right)$ & 93.4 & 24.97 & $3.543 \times 10^{-5}$ & 0.8938 & $2.309 \times 10^{3}$ & $2.463 \times 10^{-5}$ & 0.7570 & $3.499 \times 10^{4}$ \\
\hline$J \operatorname{JED}\left(220 \mathrm{~A} / \mathrm{dm}^{2}\right)$ & 97.7 & 28.04 & $6.916 \times 10^{-6}$ & 0.8984 & $7.025 \times 10^{3}$ & $1.566 \times 10^{-5}$ & 0.8623 & $5.989 \times 10^{4}$ \\
\hline
\end{tabular}
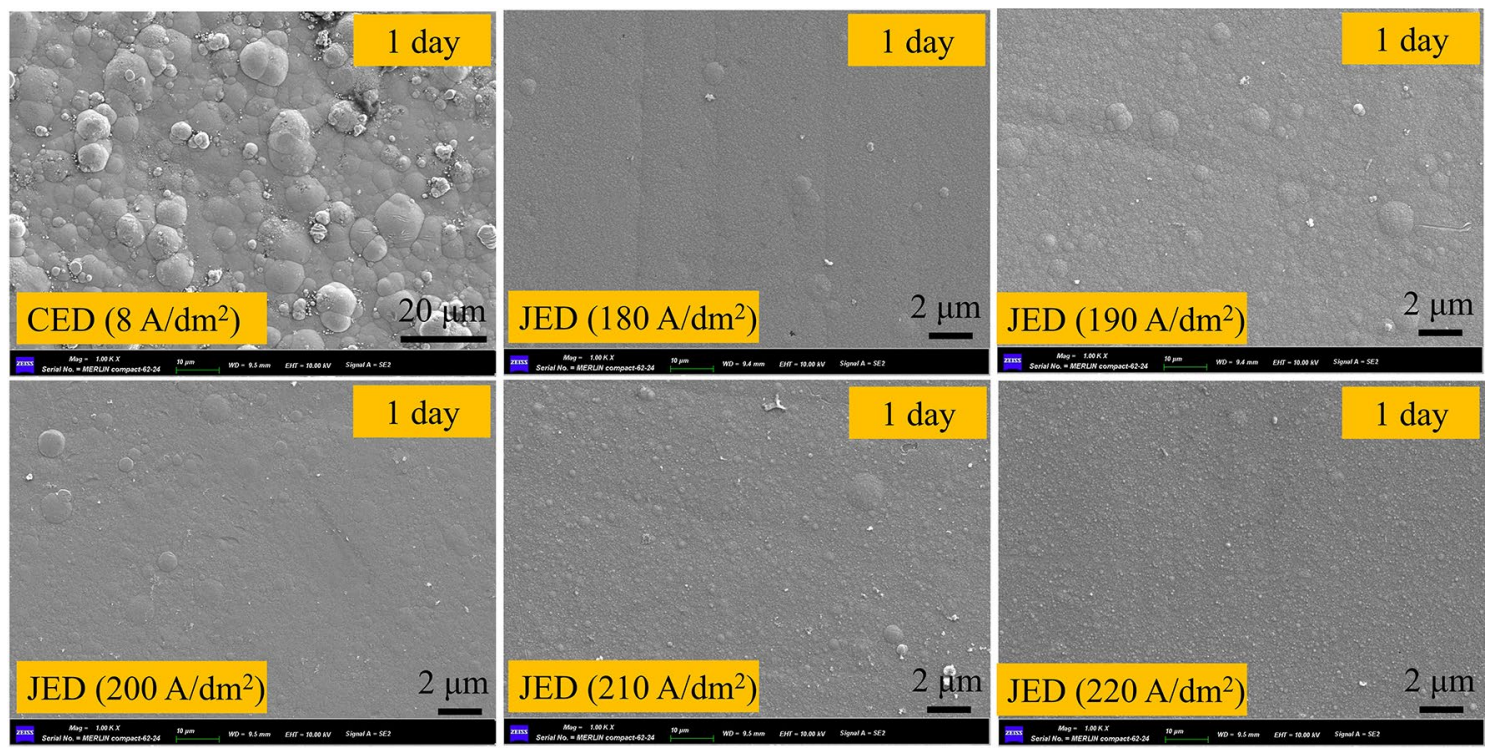

Figure 10 Surface morphologies of different Ni-SiC composite coatings after 1 day of immersion corrosion in $3.5 \mathrm{wt} \% \mathrm{NaCl}$ solution

\subsection{Adhesion Force of Ni-SiC Composite Coating with Highly Preferred (220) Orientation}

The adhesion force is an important index for judging the performance of the coating. The higher the adhesion force of the coating, the less easy it is for the coating to fall off, and the longer the service life will be. In this study, the adhesion of the $\mathrm{Ni}-\mathrm{SiC}$ composite coatings and substrate is quantitatively measured using a scratch method. Figure 14a shows the scratch morphology of the $\mathrm{Ni}-\mathrm{SiC}$ composite coating prepared using CED, and Figure $14 \mathrm{~b}-\mathrm{f}$ show the scratch morphologies of the $\mathrm{Ni}-\mathrm{SiC}$ composite coatings prepared using JED under the deposition current density of $180-220 \mathrm{~A} / \mathrm{dm}^{2}$. As shown in the elliptical frame selection area, the load corresponding to the first crack position of the coating is defined as the value of the adhesion force, which is $20.5,24.9,46.8,55.2$, 60.5 , and $61.6 \mathrm{~N}$, respectively. It can be seen that the adhesion force of the $\mathrm{Ni}-\mathrm{SiC}$ composite coating has a positive correlation with the $\mathrm{TC}(220)$ value. The higher the $\mathrm{TC}(220)$ is, the higher the adhesion force of the coating.

From a microscopic perspective, the adhesion force between the coating and substrate depends on the contact strength of the interface. A fundamental quantity determining the strength of the interface is the ideal work of the adhesion (Wad), which is the work spent on separating the interface into two free surface. The work of adhesion between the coating and substrate can be calculated using Eq. (4) [33, 34]:

$$
W_{\mathrm{ad}}=\left(E_{\mathrm{slab} 1}+E_{\mathrm{slab} 2}-E_{\text {int }}\right) / A,
$$

where $E_{\text {slab1 }}$ and $E_{\text {slab1 }}$ are the total energies of slab1 and slab2, $E_{\text {int }}$ is the total energy of the interface system including slab1 and slab2, and $A$ is the interface area. 

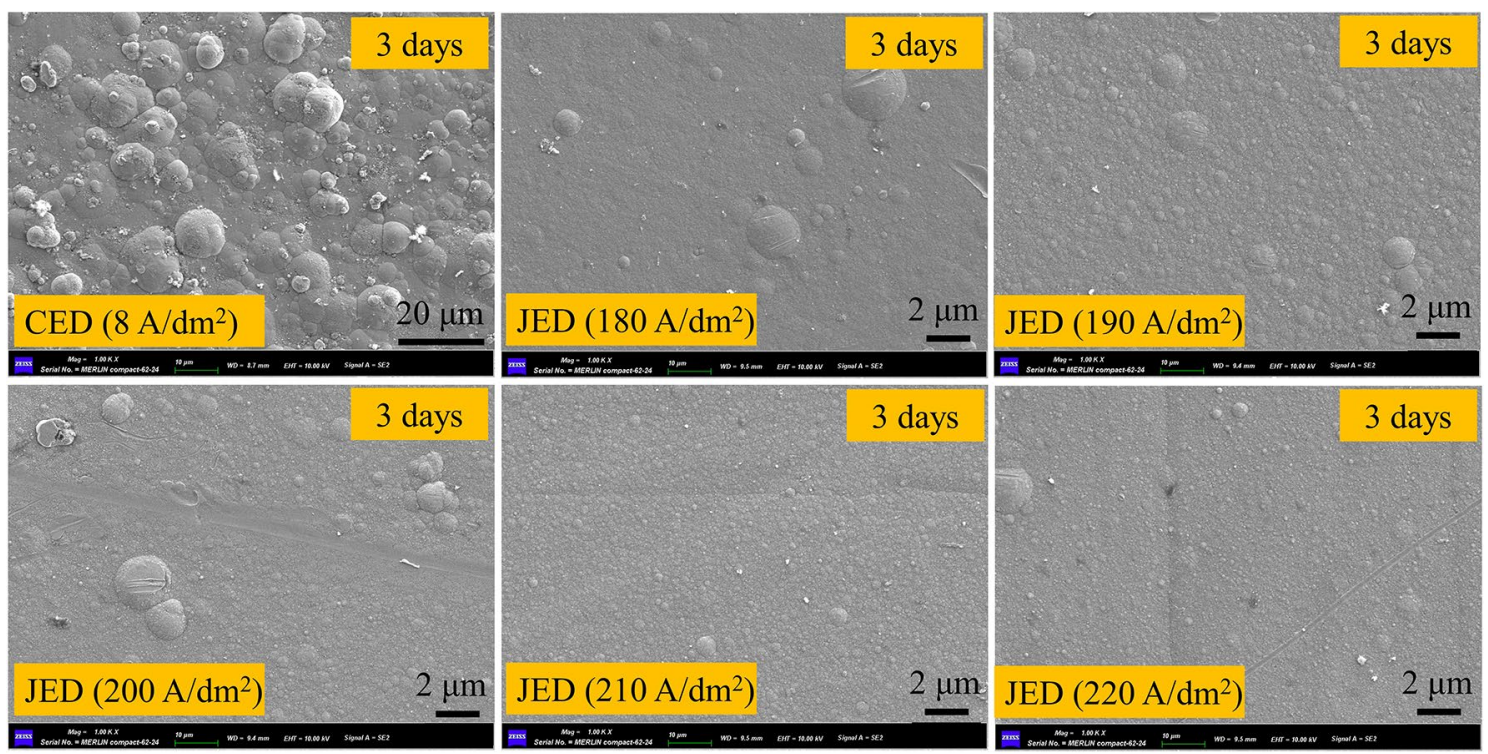

Figure 11 Surface morphologies of different Ni-SiC composite coatings after 3 days of immersion corrosion in 3.5 wt\% $\mathrm{NaCl}$ solution
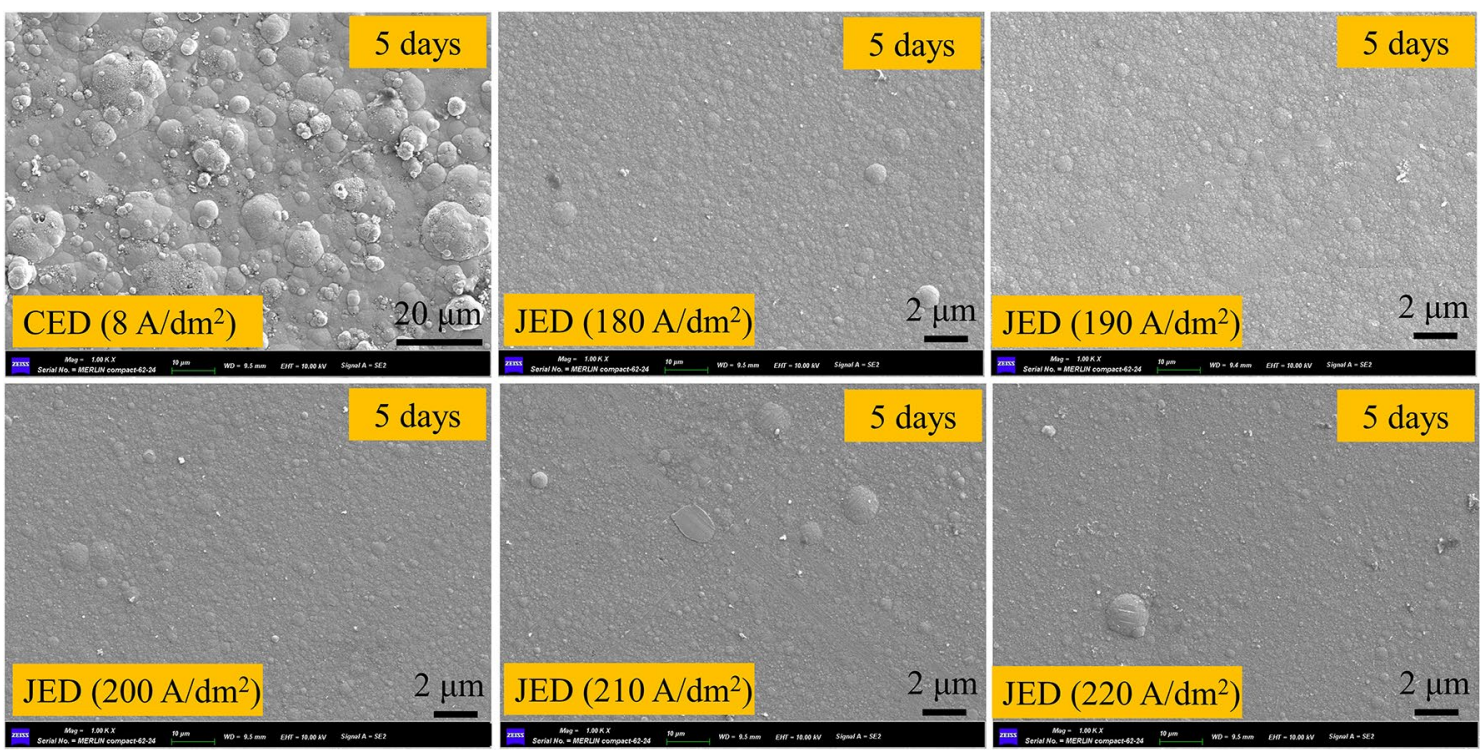

Figure 12 Surface morphologies of different Ni-SiC composite coatings after 5 days of immersion corrosion in $3.5 \mathrm{wt} \% \mathrm{NaCl}$ solution

The DFT simulation models are shown in Figure 15. The substrate is medium-carbon steel, and the main orientation of the substrate is $\mathrm{Fe}(110)$. The $W_{\mathrm{ad}}$ values of the $\mathrm{Ni}(111) / \mathrm{Fe}(110), \mathrm{Ni}(200) / \mathrm{Fe}(110)$, and $\mathrm{Ni}(220) / \mathrm{Fe}(110)$ interfaces are $3.32,3.96$, and $4.21 \mathrm{~J} / \mathrm{m}^{2}$, respectively. The
$W_{\text {ad }}$ value of the $\mathrm{Ni}(220) / \mathrm{Fe}(110)$ interface is greater than that of the $\mathrm{Ni}(111) / \mathrm{Fe}(110)$ interface and $\mathrm{Ni}(200) / \mathrm{Fe}(110)$ interface, indicating that the adhesion force between the $\mathrm{Ni}-\mathrm{SiC}$ composite coating with a highly preferred (220) orientation and substrate is higher. 

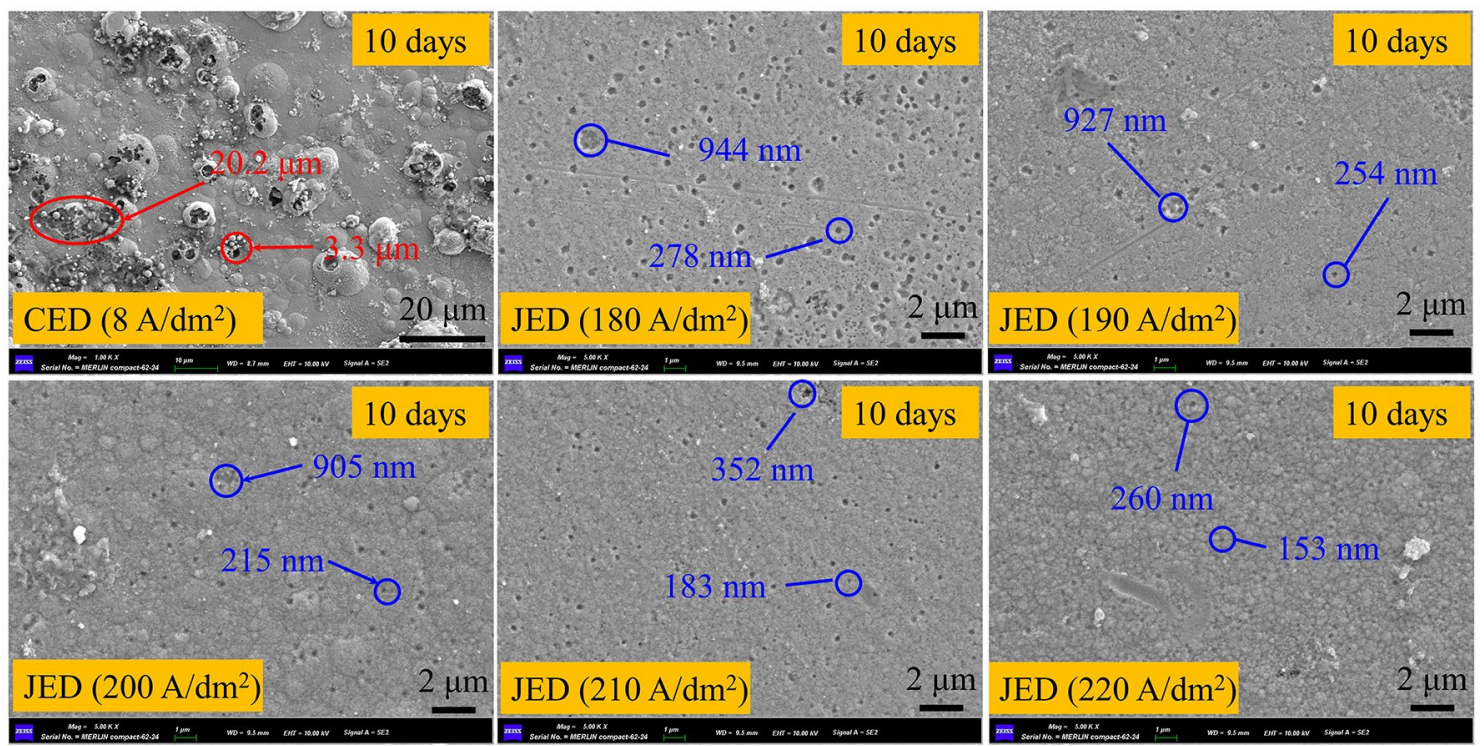

Figure 13 Surface morphologies of different Ni-SiC composite coatings after 10 days of immersion corrosion in $3.5 \mathrm{wt} \% \mathrm{NaCl}$ solution

\section{Conclusions}

(1) The grain orientation of the Ni-SiC composite coatings prepared using JED gradually evolves into (220) with an increase in the current density. The $\mathrm{Ni}-\mathrm{SiC}$ composite coating with a highly preferred (220) orientation was prepared at a current density of $220 \mathrm{~A} / \mathrm{dm}^{2}$, whereas the orientation coefficient reached $97.7 \%$.

(2) During the JED process, the high-speed jetting fluid causes the nanoparticles to break the agglomeration state and disperse evenly into the coating. Under the condition of a high current density, the deposition layer quickly fills the defects of the substrate and forms a compact and flat composite coating on the surface. The surface roughness of the $\mathrm{Ni}-\mathrm{SiC}$ composite coating with a highly preferred (220) orientation is $90.2 \%$ lower than that of the $\mathrm{Ni}-\mathrm{SiC}$ composite coating prepared using CED.
(3) The corrosion resistance of the Ni-SiC composite coatings increases with an increase in $\mathrm{TC}(220)$. Compared with the corrosion resistance of the coating prepared using CED, the corrosion resistance of the coating with the highly preferred (220) orientation prepared using JED has a $36.1 \%$ increase in corrosion potential and a $94.9 \%$ decrease in corrosion current density.

(4) A DFT simulation was conducted to calculate the ideal work of adhesion of the $\mathrm{Ni}(111) / \mathrm{Fe}(110)$, $\mathrm{Ni}(200) / \mathrm{Fe}(110)$, and $\mathrm{Ni}(220) / \mathrm{Fe}(110)$ interfaces of the $\mathrm{Ni}-\mathrm{SiC}$ composite coating, among which the $\mathrm{Ni}(220) /$ $\mathrm{Fe}(110)$ interface has a higher Wad than the $\mathrm{Ni}(111) /$ $\mathrm{Fe}(110)$ and $\mathrm{Ni}(200) / \mathrm{Fe}(110)$ interfaces. The $\mathrm{Ni}-\mathrm{SiC}$ composite coating with a highly preferred (220) orientation obtains the maximum adhesion force, which is $200 \%$ higher than that of the $\mathrm{Ni}-\mathrm{SiC}$ composite coating prepared using CED. 

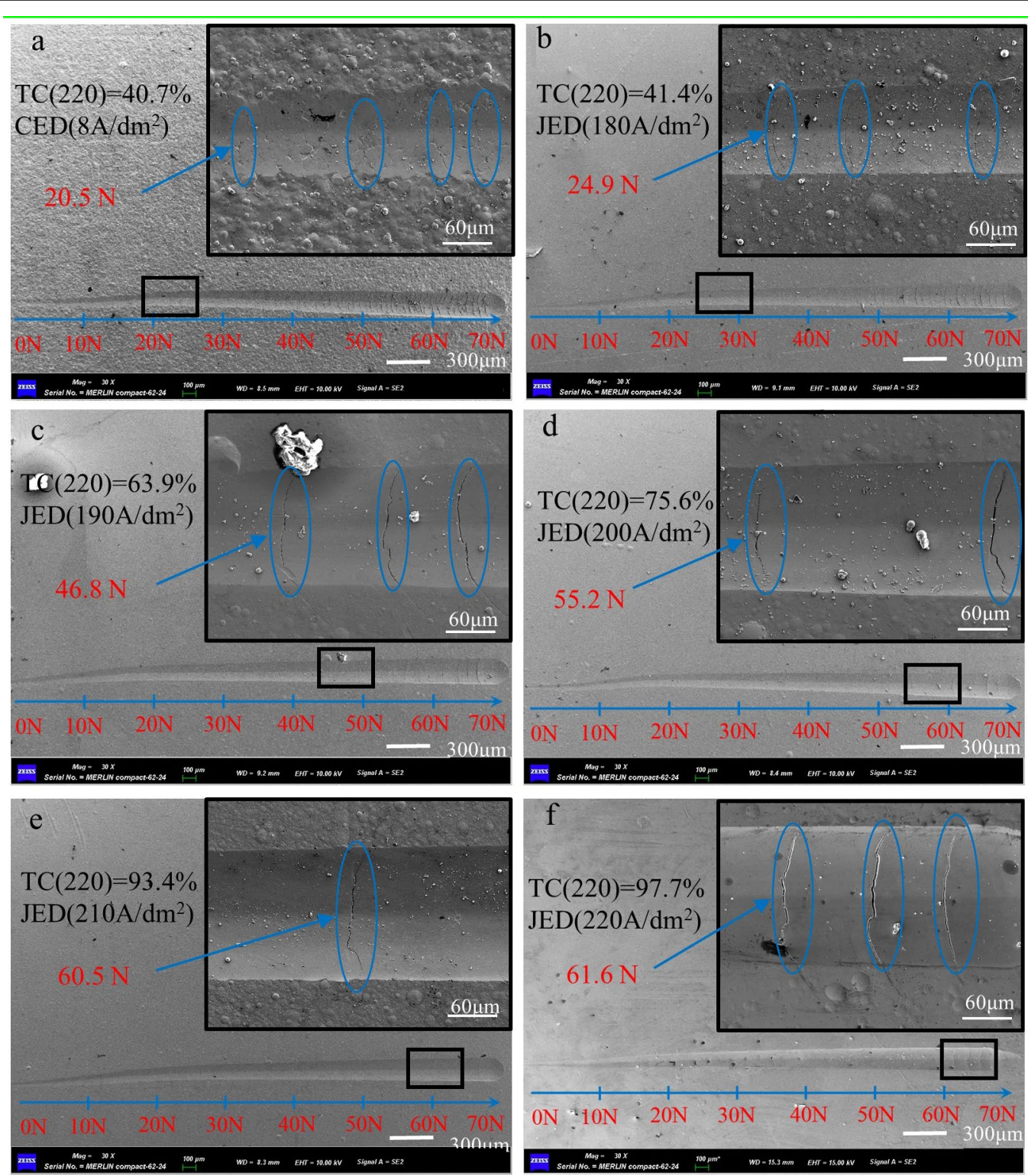

Figure 14 (a-f) Scratch morphology of different Ni-SiC composite coatings: a CED (8 A/dm²), b JED (180 A/dm²), c JED (190 A/dm²), d JED (200 A/ $\left.\mathrm{dm}^{2}\right)$, e JED $\left(210 \mathrm{~A} / \mathrm{dm}^{2}\right)$, f JED $\left(220 \mathrm{~A} / \mathrm{dm}^{2}\right)$ 

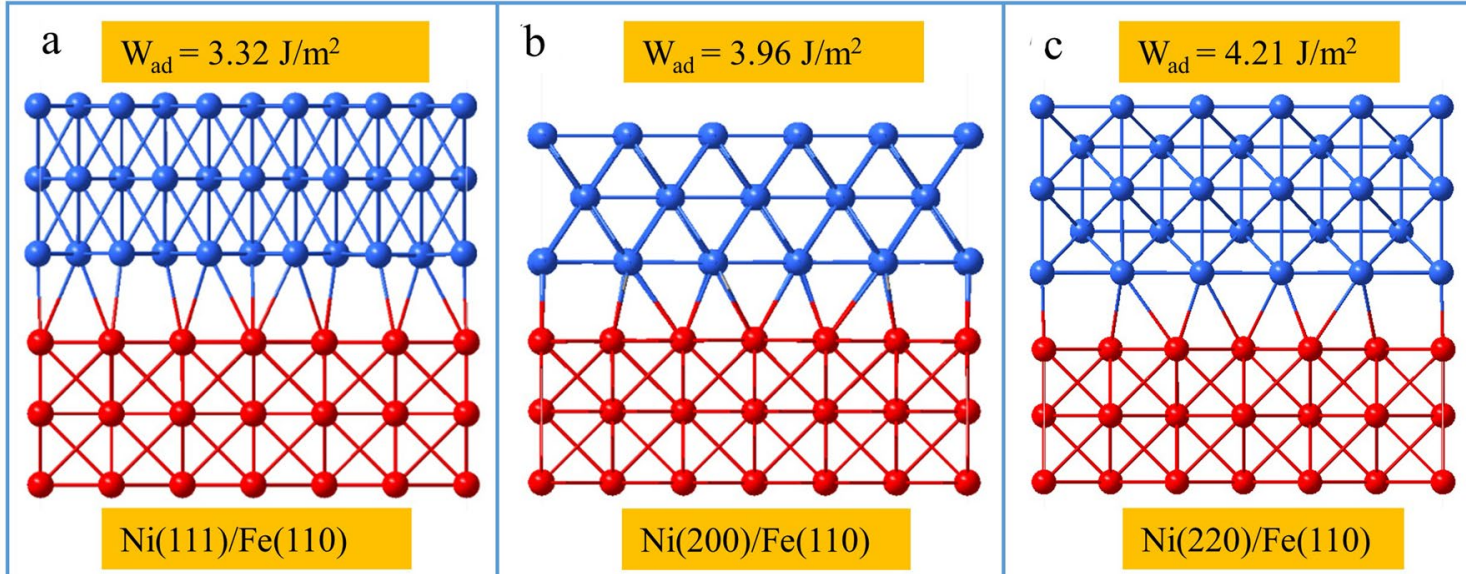

Figure 15 DFT optimized structures of a $\mathrm{Ni}(111) / \mathrm{Fe}(110), \mathbf{b} \mathrm{Ni}(200) / \mathrm{Fe}(110)$ and $\mathbf{c} \mathrm{Ni}(220) / \mathrm{Fe}(110)$ interfaces

\section{Acknowledgements}

\section{Not applicable.}

\section{Authors' Contributions}

$\mathrm{RJ}$ and $\mathrm{HJ}$ contributed equally. The manuscript was written by RJ, YL and $\mathrm{HJ}$. Experiments were designed by TD, FZ, LZ and CM. XW, QS, HD, DL, PL and BC performed the experiments. All authors have approved the final version of the manuscript.

\section{Authors' Information}

Renjie Ji received his PhD degree in Mechanical and Electronic Engineering from China University of Petroleum in 2011. He is currently a professor at China University of Petroleum, the "Hong Kong Scholar" visiting researcher of Hong Kong Polytechnic University. He is the council member of the Chinese Nontraditional Machining Society, the vice director of Youth Committee of Chinese Nontraditional Machining Society and the member of National Technical Committees 161 on Nontraditional Machine Tools of Standardization Administration of China. His research interest focuses on technology and theory of nontraditional machining.

Hui Jin, born in 1994, received his bachelor's degree of mechanical engineering from China University of Petroleum (East China) in 2016, and now working towards his PhD at China University of Petroleum (East China). His research interests include the jet electrodeposition technology and material surface strengthening technology.

Yonghong Liu received his Ph.D. degree in Mechanical Design, Manufacturing and Automation from the Harbin Institute of Technology, China, in 1996. He is currently a professor at China University of Petroleum, where he is also the Dean of College of Mechanical and Electronic Engineering. He enjoys special government allowances issued by the State Council. His research interests include the development of subsea engineering equipment, manufacturing technology of offshore equipment and fault diagnosis methodology.

Tiancong Dong, born in 1997, is currently a master candidate at Mechanism Laboratory of Mechanical Engineering, China University of Petroleum. He received his bachelor's degree from China University of Petroleum, China, in 2019. His research interests include jet electrodeposition and Electrochemical behavior of coatings.

Fan Zhang, born in 1991, is currently a PhD candidate in Prof. Renjie Ji's group at College of Mechanical and Electronic Engineering, China University of Petroleum (East China). His research interest focuses on the electrochemical energy conversion and storage using transitional metal-based catalysts.
Lilong Zhao awarded a master's degree of Mechanical Engineering (smart product design) from Nanyang Technological University Singapore in 2016. He used to be a mechanical design engineer in MCE Singapore and mechatronics engineer in ALPS-Tech China. Currently, he is a PhD candidate major in mechanical engineering at China University of Petroleum. The main research fields are intelligent manufacturing, electrical discharge machining, robot technology and ergonomics.

Xinlei Wu received his B.S. degree in Mechanical Design \& Manufacture and Automation from China University of Petroleum (East China) in 2015. He is currently working toward a Ph.D. degree in Mechanical Engineering under the supervision of Prof. Yonghong Liu. His present research interests mainly focus on nontraditional machining, intelligent manufacturing and machine learning.

Qiang Sun, born in 1990, is currently a PhD candidate at College of Mechanical and Electronic Engineering, China University of Petroleum (East China). His research interests include plasma drilling direction and plasma cutting technology.

Peng Liu received his PhD degree from China University of Petroleum (East China) in 2020. His recent research interests include reliability engineering, fault diagnosis, and Bayesian network methodology and application. E-mail: liupeng@s.upc.edu.cn.

Hang Dong received his PhD degree from China University of Petroleum (East China) in 2020. His recent research include nontraditional machining, and advanced manufacturing technology.

Chi Ma, born in 1994, is currently a PhD candidate at College of Mechanical and Electronic Engineering, China University of Petroleum (East China), China. He received his bachelor's degree from China University of Petroleum (East China), China, in 2017. His research interests include additive manufacturing and control.

Dege Li, born in 1993, received his bachelor's degree in mechanical engineering from China University of Petroleum (East China) in 2016, and now working towards his PhD at China University of Petroleum (East China). His research interests include the fabrication of microfluidic systems, ultra-fine droplet generation and manipulation, and satellite droplet mechanisms.

Baoping Cai received his BS degree in Mechanical Design, Manufacturing and Automation from the China University of Petroleum in 2006. He received his Ph.D. degree in Mechanical and Electronic Engineering from China University of Petroleum in 2012. He is a lecturer at the same university from 2013 to 2014. Currently, he is a professor at the China University of Petroleum. His research 
interests include reliability engineering, fault diagnosis, risk analysis, and Bayesian network methodology and application.

\section{Funding}

Supported by National Natural Science Foundation of China (Grant No. 51675535), Major Research Project of Shandong Province of China (Grant No. 2019GGX104068), Key Pre-Research Foundation of Military Equipment of China (Grant No. 6140923030702), National Science and Technology Major Project of China (Grant No. 2017ZX05072), Graduate Innovation Protect of China University of Petroleum (East China) (Grant No. YCX2020059) and Science and Technology Support Plan for Youth Innovation of Universities in Shandong Province of China (Grant No. 2019KJB016).

\section{Competing interests}

The authors declare no competing financial interests.

\section{Author Details}

${ }^{1}$ College of Mechanical and Electronic Engineering, China University of Petroleum (East China), Qingdao 266580, China. ${ }^{2}$ Key Laboratory of Unconventional Oil \& Gas Development, Ministry of Education, China University of Petroleum (East China), Qingdao 266580, China.

Received: 25 April 2020 Revised: 16 September 2020 Accepted: 10 November 2020

Published online: 03 December 2020

\section{References}

[1] R Li, Y Hou, B Liu, et al. Electrodeposition of homogenous $\mathrm{Ni} / \mathrm{SiO}_{2}$ nanocomposite coatings from deep eutectic solvent with in-situ synthesized $\mathrm{SiO}_{2}$ nanoparticles. Electrochimica Acta, 2016, 222: 1272-1280.

[2] B Li, D Li, W Chen, et al. Effect of current density and deposition time on microstructure and corrosion resistance of Ni-W/TiN nanocomposite coating. Ceramics International, 2019, 45(4): 4870-4879.

[3] YTao, F Ma, M Teng, et al. Designed fabrication of super high hardness Ni-B-Sc nanocomposite coating for anti-wear application. Applied Surface Science, 2019, 492: 426-434.

[4] M Alizadeh, A Cheshmpish. Electrodeposition of $\mathrm{Ni}-\mathrm{Mo} / \mathrm{Al}_{2} \mathrm{O}_{3}$ nano-composite coatings at various deposition current densities. Applied Surface Science, 2019, 466: 433-440.

[5] S Banthia, S Sengupta, S Das, et al. Synthesis and characterization of novel $\mathrm{Cu}, \mathrm{Cu}$-SiC functionally graded coating by pulse reverse electrodeposition. Applied Surface Science, 2019, 467-468: 567-579.

[6] CWang, L Shen, M Qiu, et al. Characterizations of $\mathrm{Ni}_{-} \mathrm{CeO}_{2}$ nanocomposite coating by interlaced jet electrodeposition. Journal of Alloys and Compounds, 2017, 727: 269-277.

[7] C Ma, WYu, M Jiang, et al. Jet pulse electrodeposition and characterization of $\mathrm{Ni}-\mathrm{AIN}$ nanocoatings in presence of ultrasound. Ceramics International, 2018, 44(5): 5163-5170.

[8] W Jiang, L Shen, M Qiu, et al. Preparation of Ni-SiC composite coatings by magnetic field-enhanced jet electrodeposition. Journal of Alloys and Compounds, 2018, 762: 115-124

[9] W Cui, KWang, F Xia, et al. Simulation and characterization of Ni-doped SiC nanocoatings prepared by jet electrodeposition. Ceramics International, 2018, 44(5): 5500-5505.

[10] F F Xia, W C Jia, CY Ma, et al. Synthesis and characterization of Ni-doped TiN thin films deposited by jet electrodeposition. Applied Surface Science, 2018, 434: 228-233.

[11] H Gao, W Zhen, J Ma, et al. High efficient solar hydrogen generation by modulation of Co-Ni sulfide (220) surface structure and adjusting adsorption hydrogen energy. Applied Catalysis B: Environmental, 2017, 206: 353-363.

[12] A Ponrouch, S Garbarino, E Bertin, et al. Highly porous and preferentially oriented $\{100\}$ platinum nanowires and thin films. Advanced Functional Materials, 2012, 22(19): 4172-4181.

[13] J Kim, K H Lee, SW Kim, et al. Potential-current co-adjusted pulse electrodeposition for highly (110)-oriented $\mathrm{Bi}_{2} \mathrm{Te}_{3-x} \mathrm{Se}_{x}$ films. Journal of Alloys and Compounds, 2019, 787: 767-771.
[14] J A Calderón, J E Henao, M A Gómez. Erosion-corrosion resistance of Ni composite coatings with embedded SiC nanoparticles. Electrochimica Acta, 2014, 124: 190-198.

[15] Y Zhao, L Wang, Y Sun, et al. Influences of Al and Ti particles on microstructure, internal stress and property of $\mathrm{Ni}$ composite coatings. Journal of Alloys and Compounds, 2019, 793: 314-325.

[16] M Alizadeh, $\mathrm{H}$ Safaei. Characterization of Ni-Cu matrix, $\mathrm{Al}_{2} \mathrm{O}_{3}$ reinforced nano-composite coatings prepared by electrodeposition. Applied Surface Science, 2018, 456: 195-203.

[17] J Deng, J Zhang, Y Tu, et al. Effect of BEO in the electrodeposition process of $\mathrm{Ni} /$ diamond composite coatings for preparation of ultra-thin dicing blades: Experiments and theoretical calculations. Ceramics International, 2018, 44(14): 16828-16836.

[18] R Ji, K Han, H Jin, et al. Preparation of Ni-SiC nano-composite coating by rotating magnetic field-assisted electrodeposition. Journal of Manufacturing Processes, 2020, 57: 787-797.

[19] N Guglielmi. Kinetics of the deposition of inert particles from electrolytic baths. Journal of the Electrochemical Society, 1972, 119(8): 1009.

[20] J P Celis, J R Roos, C Buelens. A mathematical model for the electrolytic codeposition of particles with a metallic matrix. Journal of the Electrochemical Society, 2019, 134(6): 1402-1408.

[21] S Xie, M Dai, S Lin, et al. Effect of bias voltage on the oxidation resistance of NiCoCrAlYTa coatings prepared by arc ion plating. Corrosion Science, 2019, 147: 330-341.

[22] X Chen, X Qin, Z Zhu, et al. Microstructural evolution and wear properties of the continual local induction cladding NiCrBSi coatings. Journal of Materials Processing Technology, 2018, 262: 257-268.

[23] Y E Sknar, O O Savchuk, IV Sknar. Characteristics of electrodeposition of $\mathrm{Ni}$ and Ni-P alloys from methanesulfonate electrolytes. Applied Surface Science, 2017, 423: 340-348.

[24] S Kumaraguru, G G Kumar, S Shanmugan, et al. Enhanced texture and microhardness of the nickel surface using $\mathrm{Bi}_{2} \mathrm{O}_{3}$ particles via electrodeposition technique for engineering application. Journal of Alloys and Compounds, 2018, 753: 740-747.

[25] B Li, W Zhang, W Zhang, et al. Preparation of Ni-W/SiC nanocomposite coatings by electrochemical deposition. Journal of Alloys and Compounds, 2017, 702: 38-50.

[26] Y LV, Y Ding, H Cui, et al. Investigation of microscopic residual stress and its effects on stress corrosion behavior of NiAl bronze alloy using in situ neutron diffraction/EBSD/tensile corrosion experiment. Materials Characterization, 2020, 164: 110351.

[27] F Zhang, R Ji, Y Liu, et al. Defect-rich engineering and F dopant comodulated $\mathrm{NiO}$ hollow dendritic skeleton as a self-supported electrode for high-current density hydrogen evolution reaction. Chemical Engineering Journal, 2020: 126037.

[28] F Zhang, R Ji, Y Liu, et al. A novel nickel-based honeycomb electrode with microtapered holes and abundant multivacancies for highly efficient overall water splitting. Applied Catalysis B: Environmental, 2020, 276: 119141.

[29] R Ji, F Zhang, Y Liu, et al. Simple synthesis of a vacancy-rich NiO 2D/3D dendritic self-supported electrode for efficient overall water splitting. Nanoscale, 2019, 11.

[30] Q Liu, X Cao, A Du, et al. Investigation on adhesion strength and corrosion resistance of $\mathrm{Ti}-\mathrm{Zr}$ aminotrimethylene phosphonic acid composite conversion coating on 7A52 aluminum alloy. Applied Surface Science, 2018, 458: 350-359.

[31] H J M Soares, O S Campos, D F Dias, et al. Chemical, morphological and corrosion characterisations of electrodeposited Ni-Fe-P coatings. Electrochimica Acta, 2018, 284: 18-23.

[32] Z Chai, C Jiang. Corrosion behavior and product film formation of $\mathrm{Ni}$-CoCu nanocrystalline coatings in neutral salt environments. Electrochimica Acta, 2019, 298: 616-629.

[33] Z Mei, S Bhattacharya, A M Yacout. Adhesion of $\mathrm{ZrN}$ and $\mathrm{Al}_{2} \mathrm{O}_{3}$ coatings on U metal from first-principles. Applied Surface Science, 2019, 473: 121-126.

[34] D Yin, X Peng, Y Qin, et al. Quantifying adhesion energy of mechanical coatings at atomistic scale. Applied Surface Science, 2011, 258(4): $1451-1455$ 